\title{
Comparative assessment of global irradiation from a satellite estimate model (CM SAF) and on-ground measurements (SIAR): a Spanish case study
}

\author{
F. Antonanzas-Torres ${ }^{\mathrm{a}, *}$, F. Cañizares ${ }^{\mathrm{b}}$, O. Perpiñán ${ }^{\mathrm{c}, \mathrm{d}}$ \\ ${ }^{a}$ EDMANS Group, University of La Rioja, Logroño, Spain. \\ ${ }^{b}$ SOLUTE Ingenieros. Avda. Cerro del Águila 3, 28703 San Sebastián de los Reyes, Spain \\ ${ }^{c}$ Electrical Engineering Department, EUITI-UPM, Ronda de Valencia 3, 28012 Madrid, Spain. \\ ${ }^{d}$ Instituto de Energía Solar, Ciudad Universitaria s/n, Madrid, Spain
}

\begin{abstract}
An analysis and comparison of daily and yearly solar irradiation from the satellite CM SAF database and a set of 301 stations from the Spanish SIAR network is performed using data of 2010 and 2011. This analysis is completed with the comparison of the estimations of effective irradiation incident on three different tilted planes (fixed, two axis tracking, north-south horizontal axis) using irradiation from these two data sources. Finally, a new map of yearly values of irradiation both on the horizontal plane and on inclined planes is produced mixing both sources with geostatistical techniques (kriging with external drift, KED)

The Mean Absolute Difference (MAD) between CM SAF and SIAR is approximately $4 \%$ for the irradiation on the horizontal plane and is comprised between $5 \%$ and $6 \%$ for the irradiation incident on the inclined planes. The MAD between KED and SIAR, and KED and CM SAF is approximately $3 \%$ for the irradiation on the horizontal plane and is comprised between $3 \%$ and $4 \%$ for the irradiation incident on the inclined planes.

The methods have been implemented using free software, available as supplementary material, and the data sources are freely available without restrictions.
\end{abstract}

Keywords: solar PV energy, global solar radiation, effective solar radiation, satellite based climate monitoring, ground based radiation, universal kriging, variogram model, CM SAF, SIAR

\section{Nomenclature}

AEMET Spanish Meteorology Agency

$\hat{\beta}_{k}$ Estimated coefficients of the deterministic model in kriging with external drift.

BSRN Baseline Surface Radiation Network

CM SAF Satellite Application Facility on Climate Monitoring

$\triangle G(0)$ Difference between $G^{C M S A F}(0)$ and $G^{S I A R}(0)$.

\footnotetext{
${ }^{*}$ Corresponding author

Email addresses: ant onanzas . fernando@gmail. com (F. Antonanzas-Torres), federico. canizares@solute.es (F. Cañizares), os car . perpinan@upm.es (O. Perpiñán)
} 
$\triangle G_{K E D}^{C M S A F}(0)$ Difference between $G^{K E D}(0)$ and $G^{C M S A F}(0)$.

$\triangle G_{K E D}^{\operatorname{SIAR}(0)}$ Difference between $G^{K E D}(0)$ and $G^{S I A R}(0)$.

$G^{C M S A F}(0)$ Yearly global irradiation on the horizontal plane data obtained by estimations from CM SAF

$G^{S I A R}(0)$ Yearly global irradiation on the horizontal plane data obtained by on-ground measurements from SIAR

$\triangle G_{e f, K E D}^{C M S A F}$ Difference between $G^{K E D}(0)$ and $G^{C M S A F}(0)$.

$\triangle G_{e f, K E D}^{S I A R}$ Difference between $G^{K E D}(0)$ and $G^{S I A R}(0)$.

$\triangle G_{e f}$ Difference between $G_{e f}^{C M S A F}$ and $G_{e f}^{S I A R}$.

$\hat{\epsilon}\left(\mathbf{s}_{\theta}\right)$ Interpolated residual in kriging with external drift.

$G^{K E D}(0)$ Yearly global irradiation on the horizontal plane estimated with kriging with external drift.

$G_{e f}^{K E D}(0)$ Yearly effective global irradiation on the inclined plane estimated with kriging with external drift.

$\gamma(\mathbf{h})$ Semivariogram function.

$\hat{\gamma}(\mathbf{h})$ Estimator of the semivariogram function.

$G_{e f}^{C M S A F}$ Yearly effective global irradiation incident on different planes estimated from data from CM SAF.

$G_{e f}^{S I A R}$ Yearly effective global irradiation incident on different planes estimated from data from SIAR.

h Separation vector between two locations.

KED Kriging with external drift

$\lambda_{i}$ Kriging weights determined by the spatial dependence structure of the residual.

LUT Look-up table

$\hat{m}\left(\mathbf{s}_{\theta}\right)$ Fitted deterministic part of the random spatial field at a new location.

MAB Mean absolute bias

$M A D$ Mean Bias Difference

$M B D$ Mean Bias Difference

OK Ordinary kriging

$q_{k}\left(\mathbf{s}_{\theta}\right)$ Auxiliary predictors obtained from the fitted values of the explanatory variable at the new location in kriging with external drift.

RMSD Biased Root Mean Square Difference 
RMSD* Unbiased Root Mean Square Difference

RTM Radiative transfer model

SIAR Agroclimatic Information System for Irrigation

SIS Shortwave incoming solar radiation

$\hat{z}$ Kriging estimation of the random spatial field

$Z(\mathbf{s})$ Random spatial field

\section{Introduction}

Nowadays, with a wide range of applications in agriculture, climate monitoring and renewable energies, research in solar irradiation is a very demanded field.

Solar irradiation can be evaluated by processing images from satellites or by on-ground measurements with pyranometers in meteorological stations. The high cost of these meteorological stations and the requirement of specific and periodic calibrations explain the low density of the existing networks in many countries, although this kind of measurements is reliable to elaborate solar irradiation maps [1]. The satellite models need to be validated and refined with high quality measurements, which are provided by on-ground stations [2]. The satellite estimates present a wide spatial and temporal coverage, but their spatial resolution is in the range of kilometres, which in many applications may not be sufficient and this can be improved with geostatistics [3]. The high degree of site dependence of solar irradiation makes geostatistics suitable to evaluate the spatial distribution of solar irradiation and to build maps with pyranometers measurements $[4,5]$.

Geostatistics were firstly applied in the study and estimation of ore resources [6], soil properties [7] and afterwards, in fields such as on-ground water analysis [8] and solar irradiation maps with kriging techniques $[3,9]$. Residual and ordinary kriging have been applied to elaborate solar irradiation maps taking into account elevation and cloudiness as significant variables [10], or topographic shadow cast and elevation [11], and also with artificial neural networks (ANN) with temperature and precipitation as inputs [12]. Kriging with external drift (KED) has been useful to develop solar irradiation maps using multiple linear regression (MLR) models [13]. Comparing solar irradiation maps obtained with different techniques and inputs is necessary to assess the divergence of the estimates. The MESOR project compared EnMetSol, Helioclim2, NASA SSE version 6, Satel-Light and SOLEMI databases obtained with satellite estimates and ESRA, PV GIS Europe, and Meteonorm version 6.1 databases generated from geostatistical models and meteorological observations in Europe [1].

Recently, the Spanish Agency of Meteorology (AEMET) has released a new solar irradiation atlas for Spain (the former was of 1984) [14] providing monthly, seasonal and annual average of global, direct and diffuse irradiation on the horizontal plane with a resolution of $3 \mathrm{~km}$ using monthly data sets from 1983 to 2005 of CM SAF. Besides, a validation process has been developed comparing CM SAF data with uninterrupted registers from 2003 to 2005 of 29 meteorological stations from the National Radiometric Network (RRN) of AEMET. On the other hand, for direct irradiation, only two ground stations, with uninterrupted data from 1992 to 2005, were selected. The Mean Absolute Deviation (MAD) obtained from this validation process for global monthly average is $12.23 \frac{\mathrm{W}}{\mathrm{m}^{2}}(6.7 \%)$, which is slightly higher than the CM SAF target of $10 \frac{\mathrm{W}}{\mathrm{m}^{2}}$. It is important to underline that the AEMET global irradiation atlas is restricted to the horizontal plane. 
This paper innovates with an analysis and comparison of solar irradiation from the CM SAF database (section 2.1) and a large set of stations, considering 301 meteorological stations (versus the 29 of the aforementioned assessment by AEMET) from the Spanish SIAR network (section 2.2), and with the estimation of effective irradiation incident on three different tracking planes.

Therefore, the contribution of this paper is threefold:

- Analysis and comparison of daily and yearly global irradiation on the horizontal plane obtained by on-ground measurements and satellite estimate data.

- Analysis and comparison of yearly global irradiation incident on different tilted planes (fixed, two axis tracking on azimuth and solar elevation, north-south horizontal axis) estimated from these two data sources.

- Elaboration of a new map of yearly values of irradiation both on the horizontal plane and on inclined planes with a smooth combination of both sources using geostatistical techniques.

The analysis comprises daily irradiation data of 2010 and 2011. The global irradiation on the horizontal plane is compared both in a daily and a yearly basis, while the effective irradiation incident on different planes is only examined in a yearly basis. In order to ease the discussion of results, the yearly analysis is carried out with the averages of 2010 and 2011.

To enable reproducible research [15], the methods have been implemented using free software (section 6). Both the source code and the data sources are freely available without restrictions.

\section{Radiation data sources}

\subsection{SAF}

The Satellite Application Facility on Climate Monitoring (CM SAF) [16] is a joint venture of the Royal Netherlands Meteorological Institute, the Swedish Meteorological and Hydrological Institute, the Royal Meteorological Institute of Belgium, the Finnish Meteorological Institute, the Deutscher Wetterdienst, Meteoswiss, the UK MetOffice, with the collaboration of the European Organization for the Exploitation of Meteorological Satellites (EUMETSAT). The CM SAF was funded in 1992 to retrieve, archive, and distribute climate data to be used for climate monitoring and climate analysis. The spatial resolution of the different products ranges from $15 \mathrm{~km}^{2}$ to $90 \mathrm{~km}^{2}$ [17].

The CM SAF provides two categories of data: operational products and climate data. The operational products are built on data that is validated with on-ground stations and then is provided in near real time to develop variability studies in diurnal and seasonal time scales. However, climate data are long-term data series to assess inter-annual variability [18].

In this study, the shortwave incoming solar radiation product (SIS) is selected with a spatial resolution of $15 \mathrm{~km}^{2}$, available as daily and monthly averages (figures A.1 and A.2). SIS collates shortwave radiation ( 0.2 to $4 \mu \mathrm{m}$ wavelength range) reaching an horizontal unit earth surface obtained by processing information from geostationary satellites (SEVIRI sensor on board of the METEOSAT Second Generation (MSG)) and also from polar satellites (AVHRR sensor on NOAA polar satellites) [17] and then validated with high-quality on-ground measurements from the Baseline Surface Radiation Network (BSRN) ${ }^{1}$.

\footnotetext{
${ }^{1}$ http://www.bsrn.awi.de/en/home/
} 
In this paper, SEVIRI data has been selected following the CM SAF recommendation of these data to be used for latitudes southern $65^{\circ} \mathrm{N}$ [19]. Validation of SEVIRI SIS data with 4 BSRN stations showed that more than $90 \%$ of the values are below the accuracy target value of $10 \frac{\mathrm{W}}{\mathrm{m}^{2}}$ (plus the uncertainty of the ground based measurements). Besides, the absence of a trend in the bias demonstrates the stability and homogeneity of the product [20].

The method for retrieving the solar surface irradiance employed by CM SAF is based on the libRadtran radiative transfer model (RTM) [22] in combination with a new approach of several parameterizations and eigenvector look-up tables (LUT). A LUT is a data structure with discrete pre-computed RTM results for a variety of atmospheric and surface states. Thus, the surface irradiance (transmittance multiplied by extraterrestrial incoming solar flux density) for a given atmospheric state can be obtained by interpolation, through the LUTs, for each satellite pixel and time. Therefore, with a LUT approach the results are similar to those obtained with a RTM reducing computation costs [23].

The CM SAF method still can be improved by a better semi-empirical adjustment of cloud effects and by improved meteorological information about aerosols and snow cover maps [23]. In fact, one main goal of the Continuous Development and Operations Phase of the CM SAF (2007-2012) is to improve all data sets in order to develop studies of inter-annual variability [17].

The figure A.1 displays a Hovmöller plot [21] with the time evolution of CM SAF daily irradiation for 2010 and 2011 averaged along $10^{\circ} \mathrm{W}$ to $5^{\circ} \mathrm{E}$, from $35.5^{\circ} \mathrm{N}$ to $44^{\circ} \mathrm{N}$. The figure A.2 displays the average of annual global irradiation on the horizontal plane for 2010 and 2011.

\subsection{SIAR}

Land-measured daily irradiation is collected from the Agroclimatic Information System for Irrigation (SIAR) [24] a free-download database operating since 1999, covering the majority of the irrigated area of Spain [25-29]. This network belongs to the Ministry of Agriculture, Food and Environment of Spain, as a tool to predict and study meteorological variables for agriculture. SIAR is composed by twelve regional centers and a national center, aiming to centralise and depurate measurements from the 361 stations of the network. The stations include SKYESP1110 (Campbell-Scientific) ${ }^{2}$ or CMP6 (KIPP\&ZONEN) ${ }^{3}$, first class pyranometers according to the World Meteorological Organization (WMO) ${ }^{4}$. The absolute accuracy is within $\pm 5 \%$ and is typically lower than $\pm 3 \%$.

The calibration of the pyranometers is performed by Tragsatec $[24,30]$ according to ISO 9847:1992 [31] using two CMP6-KIPP\&ZONEN reference pyranometers [32] on a yearly basis. Irradiation is computed on a half-hourly basis from irradiance samples recorded each $10 \mathrm{~s}$, collated through a CR10X (Campbell Scientific) datalogger within the station and then sent to the regional and national centers [24].

Data has been filtered under two assumptions: average annual irradiation must be higher than $1000 \frac{\mathrm{kWh}}{\mathrm{m}^{2}}$, and only stations with more than 600 measurement days available (out of a total of 730, 2 years) are selected. Besides, some stations have been omitted due to difficulties in the access to the coordinates of some stations, to uncompleted or spurious data series, or to stations out of the area of study. Eventually, 301 meteorological stations ${ }^{5}$ (figure A.3) and their daily global irradiation measurements on the horizontal plane for 2010 and 2011 have been considered.

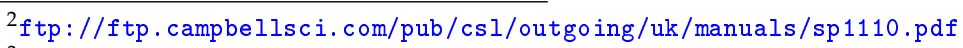

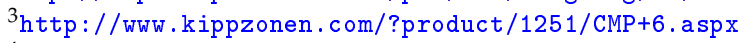

${ }^{4}$ http: //www. wmo.int/pages/index_es.html

${ }^{5}$ The name and location data of these stations are available at http://solar.r-forge.r-project.org/data/SIAR. $\operatorname{csv}$
} 


\section{Methods}

\subsection{Statistics}

The analysis is built upon the next structure (figure A.4):

- Analysis and comparison of daily and yearly global irradiation on the horizontal plane data obtained by on-ground measurements, $G^{S I A R}(0)$, and satellite data, $G^{C M S A F}(0)$. The difference between these sources is a matrix of values examined in the section 4.1 .

$$
\Delta G(0)=G^{C M S A F}(0)-G^{S I A R}(0)
$$

- Analysis and comparison of yearly global irradiation incident on different planes (fixed, two axis, north-south horizontal axis) estimated from these two data sources, $G_{e f}^{\text {SIAR }}$ and $G_{e f}^{C M S A F}$ respectively. The difference between these results is a set of three matrices examined in the section 4.1:

$$
\Delta G_{e f}=G_{e f}^{C M S A F}-G_{e f}^{S I A R}
$$

- Elaboration of a new map of yearly values with a smooth combination of both sources using geostatistical techniques, both for the horizontal plane, $G^{K E D}(0)$, and for the inclined planes, $G_{e f}^{K E D}$. The section 3.3 outlines the geostatistical interpolation technique (kriging with external drift, KED) used to combine the information from SIAR and CM SAF.

The difference between the SIAR stations and the results of the interpolation are:

$$
\begin{aligned}
\Delta G_{K E D}^{\text {SIAR }}(0) & =G^{\text {KED }}(0)-G^{\text {SIAR }}(0) \\
\Delta G_{e f, K E D}^{\text {SIAR }} & =G_{e f}^{\text {KED }}-G_{e f}^{\text {SIAR }}
\end{aligned}
$$

The difference between the CM SAF maps and the results of the interpolation are:

$$
\begin{aligned}
\Delta G_{K E D}^{C M S A F}(0) & =G^{K E D}(0)-G^{C M S A F}(0) \\
\Delta G_{e f, K E D}^{C M S A F} & =G_{e f}^{K E D}-G_{e f}^{C M S A F}
\end{aligned}
$$

These differences are summarised using several statistics: the unbiased and biased Root Mean Square Difference (RMSD* and RMSD, respectively), the Mean Bias Difference $(M B D)$ and the Mean Absolute Difference $(M A D)$ (Tables 3, 5 and 4). It must be noted that $R M S D^{2}=$ $R M S D^{* 2}+M B D^{2}$ and that $M A D \leq R M S D \leq n^{1 / 2} \cdot M A D$. The reader is referred to the reference [33] for the details on the convenience of these statistics.

These statistics are normalized by the average SIAR values when comparing CM SAF or KED with SIAR (equations (1), (2), (3) and (4)) and by the average CM SAF values when comparing KED with CM SAF (equations (5) and (6)). For example, the $R M S D^{*}, R M S D, M B D$ and 
$M A D$ corresponding to equation (1) are:

$$
\begin{aligned}
R M S D_{G 0}^{*} & =\frac{\left(\overline{\left[\left(G^{C M S A F}(0)-\overline{G^{C M S A F}}(0)\right)-\left(G^{\operatorname{SIAR}}(0)-\overline{G^{S I A R}}(0)\right)\right]^{2}}\right)^{1 / 2}}{\overline{G^{S I A R}}(0)} \\
\operatorname{RMSD}_{G 0} & =\frac{\left(\overline{\Delta G^{2}}(0)\right)^{1 / 2}}{\overline{G^{S I A R}}(0)} \\
M A D_{G 0} & =\frac{\overline{|\Delta G(0)|}}{\overline{G^{S I A R}}(0)} \\
M B D_{G 0} & =\frac{\overline{\Delta G}(0)}{\overline{G^{S I A R}}(0)}
\end{aligned}
$$

\subsection{Effective irradiation}

Three different tracking methods have been considered:

- Fixed plane, oriented towards the South and with optimum inclination angle (latitude minus $10^{\circ}$ ).

- North-South horizontal axis tracker: the axis of rotation is horizontal with respect to the ground and is on a north-south line. Panels are mounted horizontally upon the tube which will rotate on its axis to track the apparent motion of the sun through the day.

- Two-axis tracker: both azimuth and altitude are constantly changing to track the sun.

Detailed description of these methods can be found in [34]. The table 1 summarizes the calculation procedure from global daily irradiation on the horizontal plane to effective global irradiation incident on an inclined plane. It is important to highlight that this calculation procedure does not include shadow losses.

The first step of the procedure (once sun and trackers geometry equations have been computed) is to decompose the daily global irradiation on the horizontal plane in two components, direct and diffuse irradiation. Diffuse fraction, the ratio of diffuse to global irradiation, is estimated from the clearness index with the equations proposed in [35].

The second step is to build irradiance profiles from daily irradiation values. The ratio of the diffuse irradiance to diffuse irradiation is assumed to be equivalent to the ratio of extraterrestrial irradiance to extraterrestial irradiation. The ratio of global irradiance to daily global irradiation is estimated with the equations proposed in [35]. It must be noted that, because of the frequent low variability of solar irradiance, this step assumes that the average value of irradiance during a short time interval (for example, an hour) coincides numerically with the irradiation during that interval. Under this assumption the profile of irradiance incident on a surface estimated in the next step can be aggregated to produce daily irradiation.

The third step computes direct and diffuse irradiance incident on the inclined plane considering purely geometrical criteria. Direct irradiance is estimated with the solar zenith angle and the angle of incidence on the generator. Diffuse irradiance is calculated with the anisotropic model proposed in [36]. This model divides the diffuse irradiance in circumsolar (near the sun region) and isotropic, using an anisotropy index to estimate the ratio between them. The albedo is assumed to be isotropic and is estimated from the global irradiance with a reflection factor of 0.2 .

The last step estimates the effective irradiance incident on a generator subtracting dust and angle of incidence losses from the incident irradiance with the model proposed in [37]. 


\begin{tabular}{ll}
\hline Step & Method \\
\hline Sun and trackers geometry & Set of equations as provided in [34] \\
\hline $\begin{array}{l}\text { Decomposition of daily global } \\
\text { horizontal irradiation }\end{array}$ & $\begin{array}{l}\text { Correlation between diffuse fraction of horizontal ir- } \\
\text { radiation and clearness index [35] }\end{array}$ \\
\hline Estimation of irradiance & $\begin{array}{l}\text { Ratio of global irradiance to daily global irradiation } \\
{[35]}\end{array}$ \\
\hline $\begin{array}{l}\text { Estimation of irradiance on in- } \\
\text { clined surface }\end{array}$ & $\begin{array}{l}\text { The direct irradiance is calculated with geometrical } \\
\text { equations. The estimation of the diffuse component } \\
\text { makes use of the anisotropic model [36] }\end{array}$ \\
\hline Albedo irradiance & $\begin{array}{l}\text { Isotropic diffuse irradiance with reflection factor } \\
\text { equal to 0.2. }\end{array}$ \\
\hline $\begin{array}{l}\text { Effects of dirt and angle of inci- } \\
\text { dence }\end{array}$ & $\begin{array}{l}\text { Equations proposed in [37]. A low constant dirtiness } \\
\text { degree has been supposed (2\%) }\end{array}$ \\
\hline
\end{tabular}

Table 1: Calculation procedure for the estimation of effective irradiation incident on a PV generator from daily global horizontal irradiation data

\subsection{Geostatistical interpolation}

Geostatistics deals with the analysis of random fields $Z(\mathbf{s})$, where $\mathbf{s}=(x, y)$ is a location and $x, y$ its geographical coordinates. Measurements of the random field $Z$ is commonly only available at a limited set of locations (in our case, the meteorological stations of the SIAR network). In order to predict the value of $Z$ at locations without observations, the geostatistical analysis involves estimation and modelling of spatial correlation under simplifying assumptions of stationarity [38].

Assuming that the samples are representative, non-preferential and consistent, values of the field at a new location can be derived using a spatial prediction model. This geostatistical interpolation procedure is generally known as kriging [39]. A standard version of kriging is called ordinary kriging $(\mathrm{OK})$. Here the predictions are based on the model:

$$
\hat{z}(\mathbf{s})=\mu+\epsilon(\mathbf{s})
$$

where $\mu$ is the constant stationary function (global mean) and $\epsilon(\mathbf{s})$ is the spatially correlated stochastic part of variation.

The assumption of constant mean is hardly acceptable for the estimation of irradiation over a large area. Ordinary kriging was initially tried within this study, generating inaccurate estimations due to the long distances among some stations. In mountainous-heterogeneous regions such as Galicia (north of Spain), this inaccuracy was more significant than in flat-homogeneous regions, such as Castilla-La-Mancha (center of Spain).

This model can be improved including additional information from an exhaustively-sampled explanatory variable. If the explanatory variable is significantly correlated with the field $Z(\mathbf{s})$, predictions at a new location, $\mathbf{s}_{\theta}$, can be obtained modelling the deterministic and stochastic components separately:

$$
\hat{z}\left(\mathbf{s}_{\theta}\right)=\hat{m}\left(\mathbf{s}_{\theta}\right)+\hat{\epsilon}\left(\mathbf{s}_{\theta}\right)
$$


where $\hat{m}\left(\mathbf{s}_{\theta}\right)$ is the value of the fitted deterministic part at the new location, $\hat{\epsilon}\left(\mathbf{s}_{\theta}\right)$ is the interpolated residual. These two components can be derived with:

$$
\hat{z}\left(\mathbf{s}_{\theta}\right)=\sum_{k=0}^{p} \hat{\beta}_{k} q_{k}\left(\mathbf{s}_{\theta}\right)+\sum_{i=1}^{n} \lambda_{i} \epsilon\left(\mathbf{s}_{i}\right)
$$

where $\hat{\beta}_{k}$ are the estimated coefficients of the deterministic model, $q_{k}\left(\mathbf{s}_{\theta}\right)$ are the auxiliary predictors obtained from the fitted values of the explanatory variable at the new location, $\lambda_{i}$ are the kriging weights determined by the spatial dependence structure of the residual, and $\epsilon\left(\mathbf{s}_{i}\right)$ are the residual at location $\mathbf{s}_{i}$.

This improved model (equation (13)) is known as kriging with external drift (KED) or regression kriging [39]. In this paper, the explanatory variable is the irradiation on the horizontal plane estimated by CM SAF, $G^{C M S A F}(0)$, both for the irradiation on the horizontal plane and for the irradiation incident on inclined planes. Therefore, the KED method is fed with three sources of information to produce new maps:

- Yearly irradiation measurements on the horizontal plane from SIAR stations or estimations of yearly irradiation on the inclined plane based on the measurements from SIAR.

- Estimations of yearly irradiation on the horizontal plane from CM SAF as explanatory variable.

- A semivariogram function to model the spatial dependence structure of the residuals.

The semivariogram is a function defined as [40,41]:

$$
\gamma(\mathbf{h})=\frac{1}{2} \mathrm{E}(\epsilon(\mathbf{s})-\epsilon(\mathbf{s}+\mathbf{h}))^{2}
$$

where $\mathbf{h}$ is the separation vector between two locations, $\mathbf{h}=\mathbf{s}_{\mathbf{i}}-\mathbf{s}_{\mathbf{j}}$. This equation is defined under the assumption that the variance of $\epsilon$ is constant and that spatial correlation of $\epsilon$ does not depend on location $\mathbf{s}$ but only on separation distance $\mathbf{h}$. The estimator of the variogram, called the sample semivariogram is:

$$
\hat{\gamma}(\mathbf{h})=\frac{1}{2 N_{h}} \sum_{N_{h}}\left(\epsilon\left(\mathbf{s}_{i}\right)-\epsilon\left(\mathbf{s}_{j}\right)\right)^{2}
$$

with $N_{h}=\left\{\left(\mathbf{s}_{i}, \mathbf{s}_{j}\right): \mathbf{s}_{i}-\mathbf{s}_{j}=\mathbf{h}\right\}$, the set of all pairs of locations separated by vector $\mathbf{h}$. It is common to assume that the variogram is isotropic and, consequently, that the correlation at two locations depends only on the distance between them and not on the direction between them.

The sample variogram gives estimates only at observed spatial lags. Therefore, it is not enough for prediction at new locations. A common solution is to infer a parametric variogram model from the data fitting a model to the sample variogram. Some well-known parametric variogram functions are the exponential, gaussian or spherical models. The parameters of the model to be determined are the sill, the range and the nugget [39]. The table 2 displays the parameters of the variograms fitted to the SIAR data for different planes using CM SAF irradiation as explanatory variable. Figure A.5 shows the semivariances and the fitted variogram models.

The nugget effect, associated to micro-variability and measurement error, models the discontinuity of the variogram at the origin. When the nugget effect is present, the kriging method is not an exact interpolator (it does not preserve the original observations). It must be highlighted that the variograms corresponding to irradiation on the horizontal plane and on a fixed plane are the pure nugget model, that is, the residuals show no spatial auto-correlation. 


\begin{tabular}{rlrrr}
\hline & Model & Nugget & Sill & Range \\
\hline$G(0)$ & Pure nugget & 4609.11 & - & - \\
Fixed & Pure nugget & 7275.30 & - & - \\
N-S Horizontal & Spherical & 13138.08 & 6768.78 & 458.45 \\
Two Axis & Spherical & 19831.10 & 9336.59 & 478.47 \\
\hline
\end{tabular}

Table 2: Parameters of the variograms fitted to the SIAR data for different planes using CM SAF irradiation as explanatory variable.

\section{Discussion of the results}

\subsection{Comparison between SIAR and CM SAF}

The comparison of $G^{C M S A F}(0)$ and $G^{S I A R}(0)$ must be performed taking into account that the SIAR pyranometers present a tolerance of $5 \%$ (section 2.2). In figure A.6a $71 \%$ of the locations are inside the range of this pyranometer uncertainty. Outside this $5 \%$ band, $96.5 \%$ of the stations SIAR provide lower global irradiation values than CM SAF.

The relative difference increases when a tracking system is considered, $|\Delta G(0)| / G_{S I A R}(0)<$ $\left|\Delta G_{e f}\right| / G_{e f, S I A R}$ (figure A.6). Besides, the Table 3 shows that both the standard deviation of the irradiation values $\left(\sigma_{S I A R}\right.$ and $\left.\sigma_{C M S A F}\right)$ and the statistics of the differences (RMSD and MAD) increase with the application of the formulas to account for tilted surfaces. This observation is consistent with [42,43], where the variability of the effective irradiation incident on tracking planes was reported to be higher than the variability of irradiation on the horizontal plane.

No significant latitudinal behaviour is appreciated in any of the cases of figure A.6, although as per figures A.1 and A.2, solar irradiation is clearly latitudinally dependent.

In figure A.7, $\Delta G(0)$ presents a seasonal periodicity of the $5 \%$ and $95 \%$ quantiles, with a wider range for winter and more confined in summer. In this figure SIAR presents a set of samples in which $G^{\operatorname{SIAR}}(0)$ is significantly lower than $G^{C M S A F}(0)$. It may be explained due to local events not registered by the satellite resolution, or to failures in the on-ground registers, which were not detected when filtering spurious data. It is important to highlight that these extreme events are smoothed with the averages of annual sums.

In figures A.8a and A.8b, the statistics $M B D$ and $M A D$ are lower than $5 \%$ in most of the stations, although a set of outliers is appreciated in the Valencia region (middle east of Spain). In figures A.8c and A.8d, the RMSD and $R M S D^{*}$ are generally lower than $7 \%$. In a set of stations in the north of Spain in which the MBD were lower than $6 \%$, the RMSD and $R M S D^{*}$ are significantly higher, which may be explained due to the strong meteorological variability existing in the Ebro valley. In the middle Ebro valley there are marked thermal contrasts, with possible generation of orographic fog, typical in valleys. This variability generates a much more variable distribution of error magnitudes which produces higher levels of RMSD [33].

Both figures A.8 and A.6 compare irradiation on the horizontal plane from SIAR and CM SAF. However, there are remarkable differences between them. For example, there are some stations in the north of Spain clearly visible in the figure A.6 (important difference between CM SAF and SIAR) but they are invisible in the figures A.8. To explain this apparently contradictory behaviour is important to note that some stations include missing values in their data sets. The figure A.8 compares daily values with a collection of statistics computed without those missing values. However, the figure A.6 compares yearly values with missing values contributing as zeros. Therefore, those stations with a higher proportion of missing values will provide lower 
annual irradiation values, although their daily statistics could be assimilable to a station without missing values.

\subsection{Comparison between KED, SIAR and CM SAF}

The KED technique does not perform as an interpolation function when the nugget effect is not null, which occurs in this study as shown in table 2. This fact indicates that there is an intrinsic variability independent from the distance between stations. In this case, the KED behaves as a smoothing function of the SIAR values, with the external drift of CM SAF, generating a solution that differs both from SIAR and CM SAF in the positions of the meteorological stations.

Maps of global irradiation obtained with KED using CM SAF as external drift are shown in figure A.9 on the horizontal surface, fixed tilted plane, tracking system with North-South axis and two-axis tracking system. Differences between one axis tracking and fixed plane range from $0.2 \%$ to $36 \%$, and between two axis tracking and fixed plane range from $11 \%$ to $55 \%$ (figure A.10). These differences are more significant in southern Huesca $\left(42^{\circ} \mathrm{N}, 0^{\circ} \mathrm{W}\right)$, Zamora $\left(42^{\circ} \mathrm{N}\right.$, $\left.6^{\circ} \mathrm{W}\right)$, the peninsular center $\left(38^{\circ} \mathrm{N}\right.$ to $41^{\circ} \mathrm{N}, 1^{\circ} \mathrm{W}$ to $\left.6^{\circ} \mathrm{W}\right)$ and Almeria $\left(37^{\circ} \mathrm{N}, 2^{\circ} \mathrm{W}\right)$, and lower along the Cantabric coast $\left(43^{\circ} \mathrm{N}, 1^{\circ} \mathrm{W}\right.$ to $\left.9^{\circ} \mathrm{W}\right)$, due to the reduced influence of direct irradiation. Differences in irradiation estimated with KED between the two tracking systems range from $11 \%$ to $14 \%$, with higher values in the Ebro valley $\left(40^{\circ} \mathrm{N}\right.$ to $42^{\circ} \mathrm{N}, 5^{\circ} \mathrm{W}$ to $\left.2^{\circ} \mathrm{E}\right)$ and along the Mediterranean coast and lower values in Jaen $\left(38^{\circ} \mathrm{N}, 4^{\circ} \mathrm{W}\right)$.

The figures A.11, A.6b and A.12b reveal that $\left|\triangle G_{K E D}^{\text {SIAR }}(0)\right| / G_{S I A R}(0)$ and $\left|\Delta G_{e f, K E D}^{S I A R}\right| / G_{e f, S I A R}$ are slightly lower than $|\Delta G(0)| / G_{S I A R}(0)$ and $\left|\Delta G_{e f}\right| / G_{e f, S I A R}$, respectively, and correspondingly for the CM SAF values. Once again, the RMSD and $M A D$ values are very similar for all trackers and higher than those corresponding to the irradiation on the horizontal plane (Table $4)$.

In figure A.16 ${ }^{6}$, higher latitudes present higher dispersion of the differences than lower latitudes, although values remain in a $4 \%$ band. Specially, from $40^{\circ} \mathrm{N}$ to north, just when average elevation increases (figure A.3), dispersion values are higher. As already mentioned, CM SAF shows a more inaccurate behaviour when clouds or snow can appear. This fact can widen the range of differences for mountainous areas. In figure A.2 mountainous areas act as modulators of irradiation [14]. In figure A.11 (irradiation on the horizontal plane) SIAR only presents

\begin{tabular}{|c|c|c|c|c|c|c|}
\hline & $\sigma_{C M S A F}\left(\frac{\mathrm{kWh}}{\mathrm{m}^{2}}\right)$ & $\sigma_{S I A R}\left(\frac{\mathrm{kWh}}{\mathrm{m}^{2}}\right)$ & $M B D(\%)$ & $R M S D^{*}(\%)$ & $R M S D(\%)$ & $M A D(\%)$ \\
\hline G0 & 92.50 & 102.09 & 3.41 & 4.44 & 5.60 & 4.19 \\
\hline Fixed & 88.16 & 112.09 & 3.59 & 5.21 & 6.33 & 4.69 \\
\hline N-S Horiz & 146.21 & 170.28 & 4.24 & 5.93 & 7.30 & 5.57 \\
\hline Two-axis & 155.99 & 195.63 & 4.33 & 6.36 & 7.69 & 5.84 \\
\hline
\end{tabular}

Table 3: Statistics of the yearly irradiation values from CMSAF and SIAR. The RMSD, RMSD*, $M B D$ and $M A D$ statistics are calculated with adimensionalized differences using $G_{y}^{S I A R}(0)$ or $G_{e f, y}^{S I A R}$ as normalization factors. 
higher irradiation than CM SAF in the very north of Spain. Nevertheless, the variability of the previous map is in the range of $5 \%$, which stands within the uncertainty band.

In figure A.16, relative differences of irradiation incident on tilted planes reach values of $10 \%$ for fixed systems and $-10 \%$ for one-axis and two-axis with higher dispersion in these last cases. KED shows higher values than CM SAF especially in the north area for fixed systems, and to a lesser extent, for one and two axis around the Pyrenees area. The RMSD and MAD values are very similar for all trackers and higher than those corresponding to the irradiation on the horizontal plane (Table 5).

One possible explanation for the positive values of relative differences existing in the area of Pyrenees would come from the influence of the terrain elevation on satellite methods [44]. The solar irradiation dependence with altitude is not well described in the satellite retrieving methods yet. In a mountain area each pixel cover an area of very varying altitude and therefore the irradiation estimations have more uncertainty than in flat terrains. Besides, satellite methods have difficulties in distinguishing snow and ice from clouds typically at mountain areas. An underestimation of the amount of water vapour and/or aerosols produces an overestimation in the values of CM SAF. Also the uncertainties associated with estimating the clouds cover plays an important role in divergence observed [14]. A special version of CM SAF for mountainous areas is being developed using methods proposed by and maybe, after this update, relative differences at those areas will decrease [45].

\begin{tabular}{rcccccc}
\hline & $\sigma_{K E D}\left(\frac{\mathrm{kWh}}{\mathrm{m}^{2}}\right)$ & $\sigma_{\text {SIAR }}\left(\frac{\mathrm{kWh}}{\mathrm{m}^{2}}\right)$ & $M B D(\%)$ & $R M S D^{*}(\%)$ & $R M S D(\%)$ & $M A D(\%)$ \\
\hline G0 & 72.67 & 102.09 & 0.00 & 4.28 & 4.28 & 3.02 \\
Fixed & 63.01 & 112.09 & 0.00 & 5.23 & 5.23 & 3.66 \\
N-S Horiz & 122.67 & 170.28 & 0.00 & 4.60 & 4.60 & 3.32 \\
Two-axis & 131.11 & 195.63 & 0.00 & 5.01 & 5.01 & 3.63 \\
\hline
\end{tabular}

Table 4: Statistics of the yearly horizontal irradiation values from KED and SIAR. The RMSD, $R M S D^{*}, M B D$ and $M A D$ statistics are calculated with adimensionalized differences using $G_{y}^{S I A R}(0)$ or $G_{e f, y}^{S I A R}$ as normalization factors.

\section{Conclusions}

An analysis and comparison of daily and yearly solar irradiation from the satellite CM SAF database and a set of 301 stations from the Spanish SIAR network is performed using data of

\begin{tabular}{rcccccc}
\hline & $\sigma_{K E D}\left(\frac{\mathrm{kWh}}{\mathrm{m}^{2}}\right)$ & $\sigma_{C M S A F}\left(\frac{\mathrm{kWh}}{\mathrm{m}^{2}}\right)$ & $M B D(\%)$ & $R M S D^{*}(\%)$ & $R M S D(\%)$ & $M A D(\%)$ \\
\hline G0 & 112.24 & 142.86 & -2.52 & 1.84 & 3.12 & 2.86 \\
Fixed & 93.06 & 148.43 & -2.31 & 2.93 & 3.73 & 3.42 \\
N-S Horiz & 215.48 & 239.73 & -3.48 & 2.62 & 4.35 & 3.60 \\
Two-axis & 242.62 & 265.95 & -3.67 & 2.75 & 4.59 & 3.82 \\
\hline
\end{tabular}

Table 5: Statistics of the yearly horizontal irradiation values from KED and CM SAF (figures A.11, A.13, A.14 and A.15). The RMSD, RMSD* $M B D$ and MAD statistics are calculated with adimensionalized differences using $G_{y}^{C M S A F}(0)$ or $G_{e f, y}^{C M S A F}$ as normalization factors. 
2010 and 2011. This analysis is completed with the comparison of the estimations of effective irradiation incident on three different tilted planes (fixed, two axis tracking, north-south horizontal axis) using irradiation from these two data sources. Finally, a new map of yearly values of irradiation both on the horizontal plane and on inclined planes is produced mixing both sources with geostatistical techniques (kriging with external drift, KED).

The comparison between the irradiation values from SIAR, CM SAF and KED is performed in the context of the SIAR pyranometers tolerance $(5 \%)$. The difference of global irradiation from SIAR and CM SAF at $71 \%$ of the locations are inside the range of this pyranometer uncertainty. Outside this $5 \%$ band, $96.5 \%$ of the SIAR stations provide lower global irradiation values than CM SAF. The relative difference increases when a tracking system is considered: both the standard deviation of the irradiation values $\left(\sigma_{S I A R}\right.$ and $\left.\sigma_{C M S A F}\right)$ and the statistics of the differences (RMSD and MAD) increase with the use of tracking systems.

The Mean Absolute Difference (MAD) between CM SAF and SIAR is approximately $4 \%$ for the irradiation on the horizontal plane and is comprised between $5 \%$ and $6 \%$ for the irradiation incident on the inclined planes.

The use of kriging with external drift reduces the difference with SIAR and CM SAF, both for the horizontal plane and for inclined planes. The MAD between KED and SIAR, and KED and CM SAF is approximately $3 \%$ for the irradiation on the horizontal plane and is comprised between $3 \%$ and $4 \%$ for the irradiation incident on the inclined planes.

\section{Software}

The methods described in this paper have been implemented using the free software environment $R$ [46] and several contributed packages, namely: gstat [40] and sp [41] for the geostatistical analysis; solaR [47] for the solar geometry, irradiation and PV energy calculations; raster [48] for spatial data manipulation and analysis, and rasterVis [49] for spatial data visualisation methods.

The source code is available at https://github.com/oscarperpinan/CMSAF-SIAR.

\section{Acknowledgements}

This paper is inspired by a previous work developed by Fernando Antoñanzas Torres, Federico Cañizares Jover, Rafael Morales Cabrera and Manuel Ojeda Fernández and directed by Oscar Perpiñán Lamigueiro, as their Master's Final Project in the context of the Master in Renewable Energy and the Energy Market at the EOI School of Industrial Organisation.

\section{References}

[1] H. G. Beyer, J. Polo, M. Suri, J. L. Torres, E. Lorenz, S. Müller, C. Hoyer-Klick, P. Ineichen, Report on benchmarking of radiation products, Technical report, Management and Exploitation of Solar Resource Knowledge (2009).

[2] J. Tovar-Pescador, D. Pozo-Vázquez, J. A. Ruiz-Arias, J. Batlles, G. López, J. L. Bosch, On the use of the digital elevation model to estimate the solar radiation in areas of complex topography, Meteorological Applications 13 (03) (2006) 279-287. arXiv: http: //journals . cambridge.org/article_S1350482706002258.

[3] G. G. Merino, D. Jones, D. E. Stooksbury, K. G. Hubbard, Determination of semivariogram models to krige hourly and daily solar irradiance in western Nebraska, Journal of Applied Meteorology 40 (6) (2001) 1085-1094. 
[4] H. G. Beyer, G. Czeplak, U. Terzenbach, L. Wald, Assessment of the method used to construct clearness index maps for the new European Solar Radiation Atlas (ESRA), Solar Energy 61 (6) (1997) 389-397.

[5] S. Rehman, S. G. Ghori, Spatial estimation of global solar radiation using geostatistics, Renewable Energy 21 (3-4) (2000) 583-605.

[6] M. David, Geostatistical ore reserve estimation, Elsevier Scientific Publishing Company, 1977.

[7] W. Sun, B. Minasny, A. McBratney, Analysis and prediction of soil properties using local regression-kriging, Geoderma 171-172 (2012) 16-23.

[8] F.-g. Yang, S.-y. Cao, X.-n. Liu, K.-j. Yang, Design of groundwater level monitoring network with ordinary kriging, Journal of Hydrodynamics, Ser. B 20 (2008) 339-346.

[9] M. Hutchinson, T. Booth, J. McMahon, H. Nix, Estimating monthly mean values of daily total solar radiation for Australia, Solar Energy 32 (2) (1984) 277 - 290.

[10] J. Ruiz-Arias, D. Pozo-Vázquez, F. Santos-Alamillos, V. Lara-Fanego, J. Tovar-Pescador, A topographic geostatistical approach for mapping monthly mean values of daily global solar radiation: A case study in southern Spain, Agricultural and Forest Meteorology 151 (12) (2011) 1812-1822.

[11] H. Alsamamra, J. A. Ruiz-Arias, D. Pozo-Vázquez, J. Tovar-Pescador, A comparative study of ordinary and residual kriging techniques for mapping global solar radiation over southern Spain, Agricultural and Forest Meteorology 149 (8) (2009) 1343-1357.

[12] A. Moreno, M. A. Gilabert, B. Martínez, Mapping daily global solar irradiation over Spain: A comparative study of selected approaches, Solar Energy 85 (2011) 2072-2084.

[13] F. Evrendilek, C. Ertekin, Statistical modeling of spatio-temporal variability in monthly average daily solar radiation over Turkey, Sensors 7 (11) (2007) 2763-2778.

[14] J. M. Sancho, J. Riesco, C. Jiménez, M. Sánchez, J. Montero, M. López, Atlas de radiación solar, Technical report, Agencia Estatal de Meteorología (2012).

URL http://www.aemet.es/es/serviciosclimaticos/datosclimatologicos/atlas_ radiacion_solar

[15] The Yale Law School Roundtable on Data and Code Sharing, Reproducible research, Computing in Science \& Engineering 12 (2010) 8-13.

[16] The Satellite Application Facility on Climate Monitoring, CMSAF, http://www . cmsaf .eu (2011).

[17] J. Schulz, P. Albert, H.-D. Behr, D. Caprion, H. Deneke, S. Dewitte, B. Dürr, P. Fuchs, A. Gratzki, P. Hechler, R. Hollmann, S. Johnston, K.-G. Karlsson, T. Manninen, R. Müller, M. Reuter, A. Riihelä, R. Roebeling, N. Selbach, A. Tetzlaff, W. Thomas, M. Werscheck, E. Wolters, A. Zelenka, Operational climate monitoring from space: the Eumetsat Satellite Application Facility on Climate Monitoring (CM-SAF), Atmospheric Chemistry and Physics 9 (2009) 1687-1709.

URL http://www . atmos-chem-phys .net/9/1687/2009/acp-9-1687-2009.pdf

[18] J. Trentmann, C. Träger-Chatterjeea, R. Müller, Product user manual. Surface radiation products, Technical report, CM-SAF (2010). 
[19] CM SAF Technical Team, Climate monitoring SAF annual validation report 2008, Technical report, CM SAF (2009).

[20] CM SAF Technical Team, EUMETSAT climate monitoring SAF annual product quality assessment report 2010, Technical report, CM SAF (2011).

[21] E. Hovmöller, The trough-and-ridge diagram, Tellus 1 (2) (1949) 62-66.

[22] B. Mayer, A. Kylling, Technical note: The libRadtran software package for radiative transfer calculations - description and examples of use, Atmospheric Chemistry and Physics 5 (7) (2005) 1855-1877.

URL http://www . atmos-chem-phys .net/5/1855/2005/acp-5-1855-2005.pdf

[23] R. Müeller, C. Matsoukas, A. Gratzki, H. Behr, R. Hollmann, The CM SAF operational scheme for the satellite based retrieval of solar surface irradiance , a LUT based eigenvector hybrid approach, Remote Sensing of Environment 113 (5) (2009) 1012 - 1024.

[24] Ministerio de Medio Ambiente, Rural y Marino (2011), URL http:///www . marm.es/siar/Informacion.asp

[25] J. Estévez, P. Gavilán, J. Giráldez, Guidelines on validation procedures for meteorological data from automatic weather stations, Journal of Hydrology 402 (2011) 144-154.

[26] I. Pagola, M. Gastón, C. Fernández-Peruchena, S. Moreno, L. Ramirez, New methodology of solar radiation evaluation using free access databases in specific locations, Renewable Energy 35 (12) (2010) 2792-2798.

[27] H. Nieto, I. Aguado, E. Chuvieco, I. Sandholt, Dead fuel moisture estimation with MSGSEVIRI data. Retrieval of meteorological data for the calculation of the equilibrium moisture content, Agricultural and Forest Meteorology 150 (2010) 861-870.

[28] P. Gavilán, I. Lorite, S. Tornero, J. Berengena, Regional calibration of Hargreaves equation for estimating reference ET in a semiarid environment, Agricultural Water Management 81 (3) (2006) 257-281.

[29] J. Almorox, C. Hontoria, M. Benito, Models for obtaining daily global solar radiation with measured air temperature data in Madrid (Spain), Applied Energy 88 (5) (2011) 1703-1709.

[30] Tragsatec, Redes de control agro-meteorológico y automatización de redes de riego (2012). URLhttp://www.tragsa.es/es/lineas-de-actividad/regadios-y-tecnologia-del-agua/ Paginas/redes-de-control-agro-meteorologico-y-automatizacion-de-redes-de-riego. aspx

[31] ISO TC 180/SC 1, ISO 9847:1992: Solar energy - Calibration of field pyranometers by comparison to a reference pyranometer.

[32] F. Padilla, Estaciones agroclimáticas del SIAR. Sensores, ubicaciones y mantenimiento (2011).

URL http://www.chil.org/document/2217

[33] C. J. Willmott, K. Matsuura, Advantages of the mean absolute error (MAE) over the root mean square error (RMSE) in assessing average model performance, Climate Research 30 (2005) 79-82. 
[34] O. Perpiñán, Energía Solar Fotovoltaica, 2012.

URL http://procomun . wordpress. com/documentos/libroesf/

[35] M. Collares-Pereira, A. Rabl, The average distribution of solar radiation: correlations between diffuse and hemispherical and between daily and hourly insolation values, Solar Energy 22 (1979) 155-164.

[36] J. E. Hay, D. C. McKay, Estimating solar irradiance on inclined surfaces: A review and assessment of methodologies, International Journal of Solar Energy (3) (1985) 203-240.

[37] N. Martin, J. M. Ruíz, Calculation of the PV modules angular losses under field conditions by means of an analytical model, Solar Energy Materials \& Solar Cells 70 (2001) 25-38.

[38] R. S. Bivand, E. J. Pebesma, V. Gomez-Rubio, Applied spatial data analysis with R, Springer, NY, 2008.

URL http://www. asdar-book.org/

[39] T. Hengl, A practical guide to geostatistical mapping, 2009.

URL http://spatial-analyst.net/book/

[40] E. J. Pebesma, Multivariable geostatistics in S: the gstat package, Computers and Geosciences 30 (2004) 683-691.

[41] E. J. Pebesma, R. S. Bivand, Classes and methods for spatial data in R, R News 5 (2) (2005) 9-13.

URL http://CRAN.R-project.org/doc/Rnews/

[42] M. Súri, T. Huld, E. Dunlop, J. Hofierka, Solar resource modelling for energy applications: digital terrain modelling, Springer Berlin Heidelberg, 2007, 259-273.

[43] O. Perpiñán, Statistical analysis of the performance and simulation of a two-axis tracking PV system, Solar Energy 83 (11) (2009) 2074-2085.

URL http://procomun.wordpress.com/documentos/articulos/

[44] T. Huld, R. Müller, A. Gambardella, A new solar radiation database for estimating PV performance in Europe and Africa, Solar Energy 86 (6) (2012) 1803-1815.

[45] B. Dürr, A. Zelenka, Deriving surface global irradiance over the Alpine region from METEOSAT Second Generation data by supplementing the HELIOSAT method, International Journal of Remote Sensing 30 (22) (2009) 5821-5841.

[46] R: A language and environment for statistical computing, R Foundation for Statistical Computing, Vienna, Austria, ISBN 3-900051-07-0 (2012).

URL http://www.R-project.org

[47] O. Perpiñan, solaR: Solar radiation and photovoltaic systems with R, Journal of Statistical Software 50 (9) (2012) 1-32.

URL http://www.jstatsoft.org/v50/i09/

[48] R. J. Hijmans, J. van Etten, raster: Geographic analysis and modeling with raster data, R package version 1.9-82 (2012).

URL http://CRAN.R-project. org/package=raster

[49] O. Perpinan, R. Hijmans, rasterVis: Visualization methods for the raster package, R package version 0.10-9 (2012).

URL http://CRAN.R-project .org/package=rasterVis 
Appendix A. Figures 


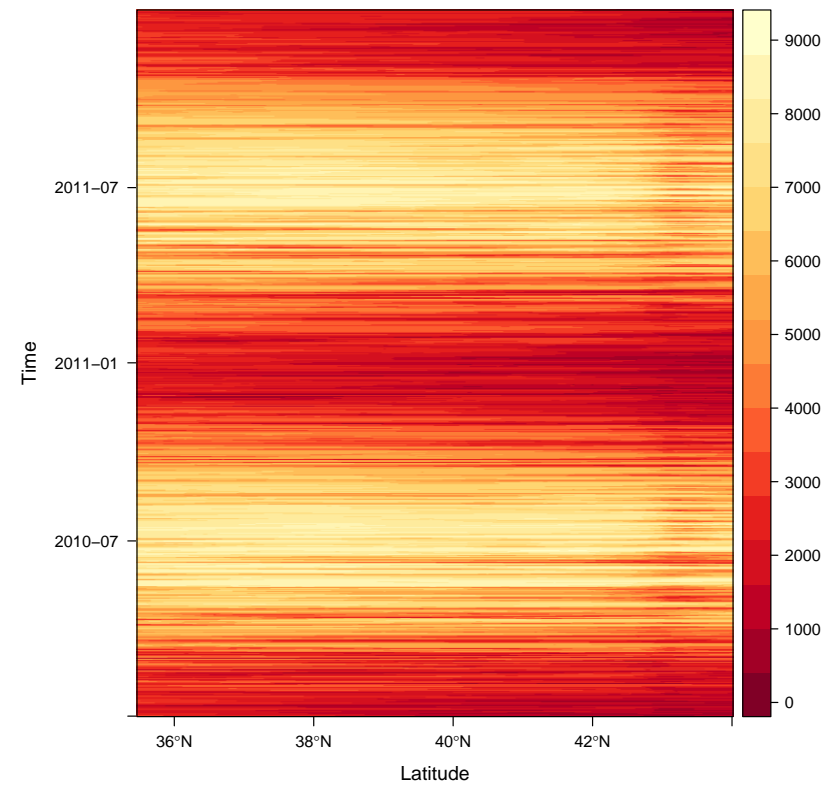

Figure A.1: Hovmöller plot with the time evolution of the daily horizontal irradiation $\left(\frac{\mathrm{Wh}}{\mathrm{m}^{2}}\right)$ as published by $\mathrm{CM} \mathrm{SAF}$, averaged along $10^{\circ} \mathrm{W}$ to $5^{\circ} \mathrm{E}$.

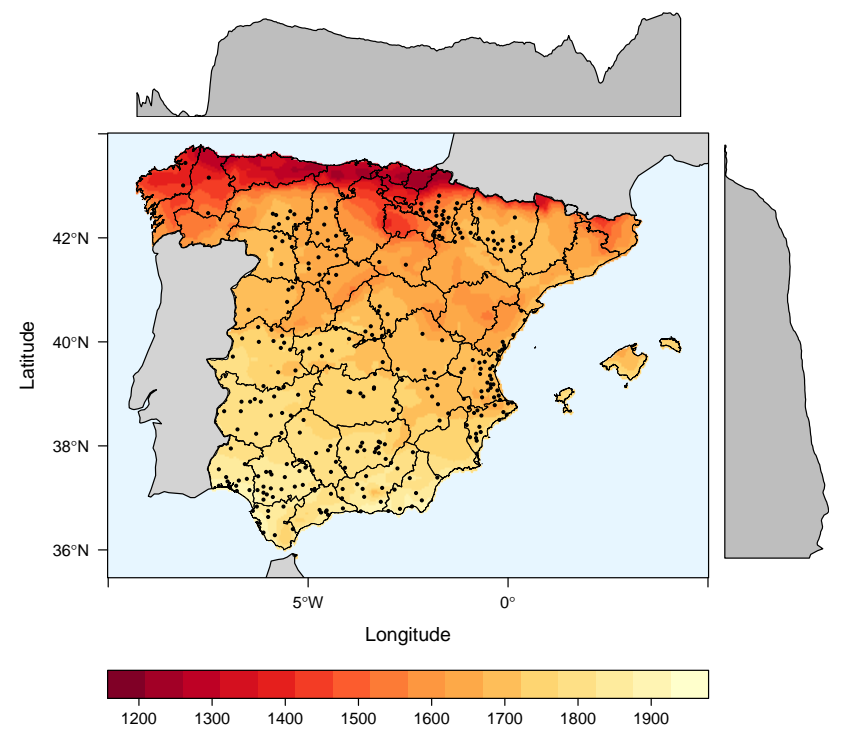

Figure A.2: Average of yearly horizontal irradiation $\left(\frac{\mathrm{kWh}}{\mathrm{m}^{2}}\right)$ on the horizontal plane as published by CM SAF during 2010 and 2011. 


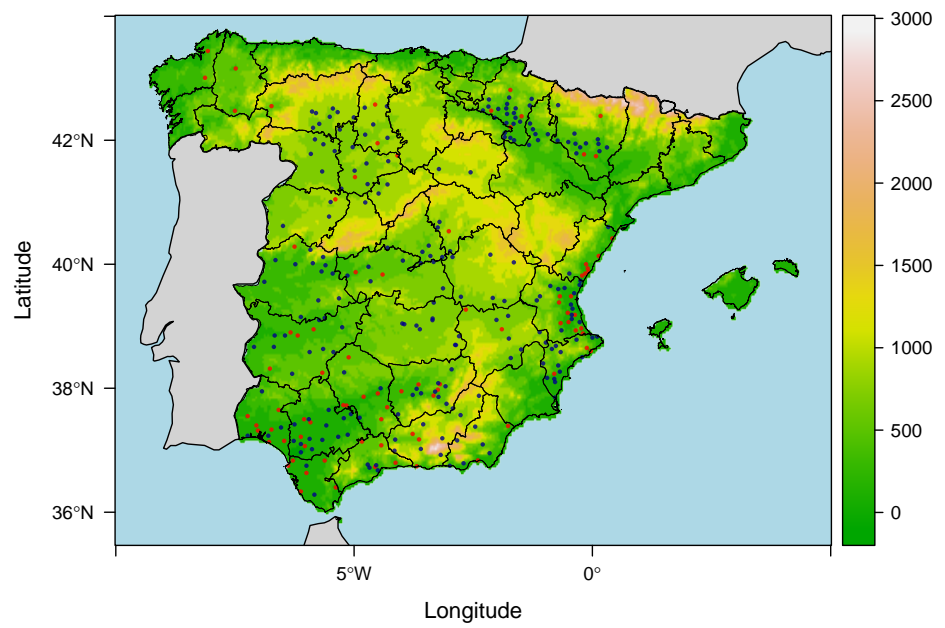

Figure A.3: Meteorological stations of the SIAR network. The color key indicates the altitude (m). Those stations whose average yearly absolute difference from the CM SAF values is higher than $5 \%$ are displayed with red points. 


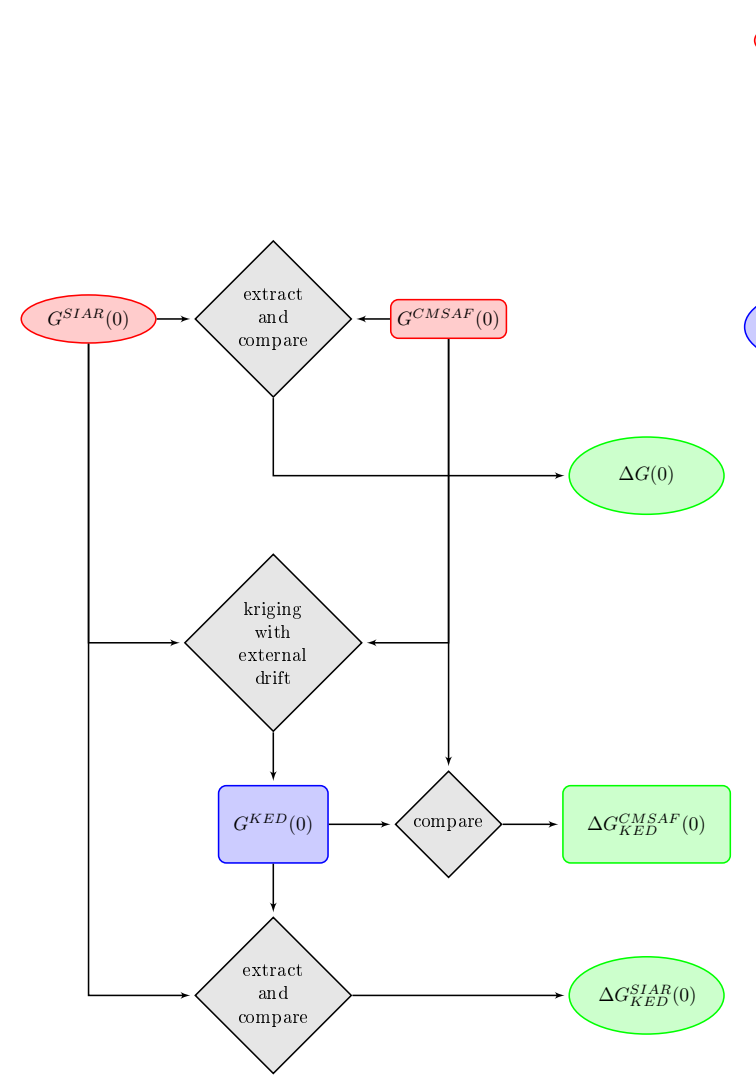

(a) Horizontal irradiation comparison

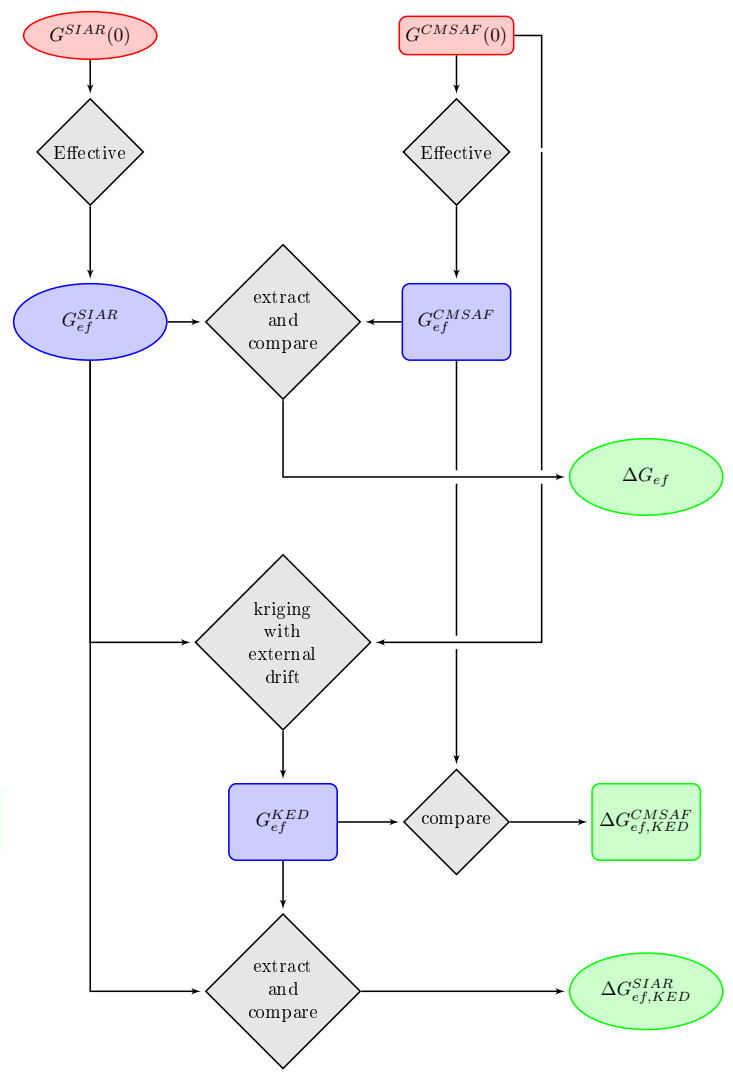

(b) Effective irradiation comparison

Figure A.4: Organization of the analysis procedure. Ellipses represent point data sets (values from the meteorological stations, for example) and rectangles denote raster maps (values from CM SAF, for example). The red color is used to identify the original sources, green for comparison results, and blue for transformation results (geostatistical interpolation or effective irradiation). 


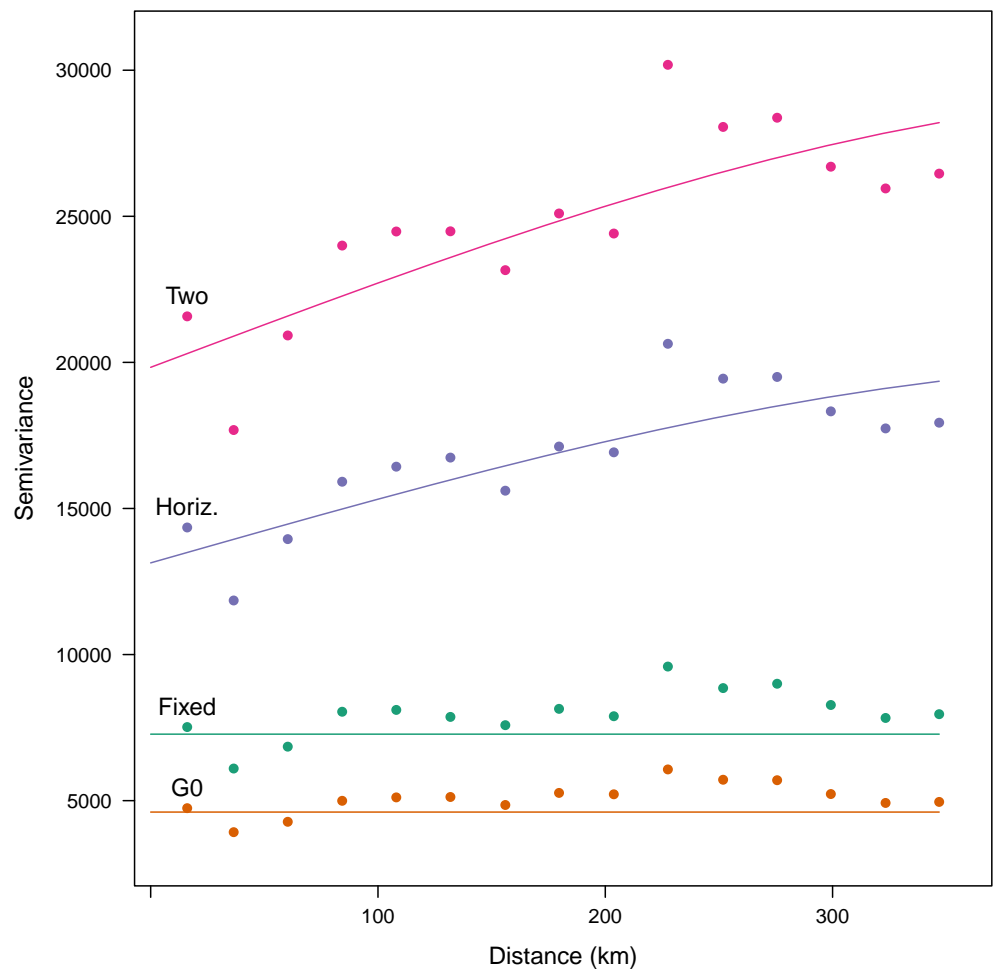

Figure A.5: Semivariances and variograms fitted to the SIAR data for different planes using CM SAF irradiation as explanatory variable. 


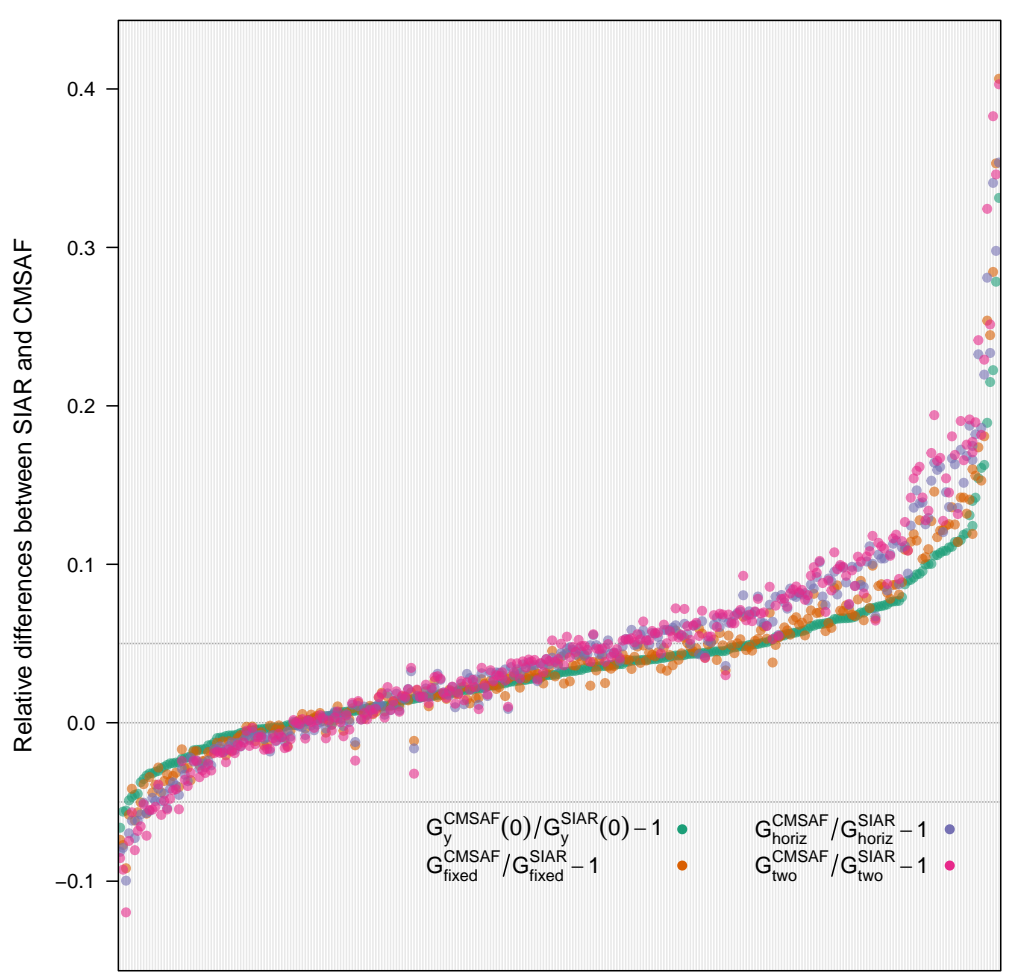

(a) Dotplot
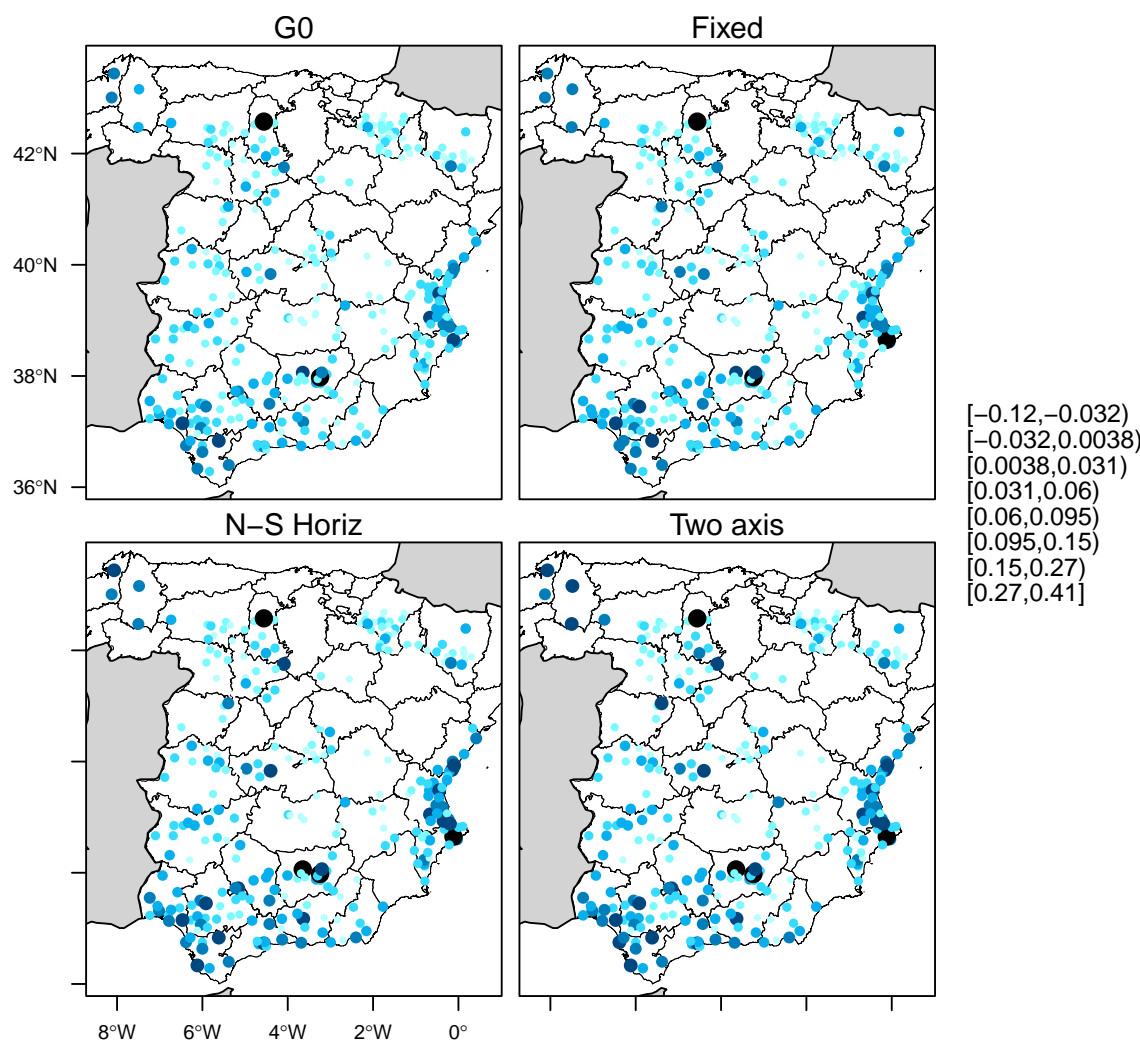

(0.032,0.0038)

$0.0038,0.031)$

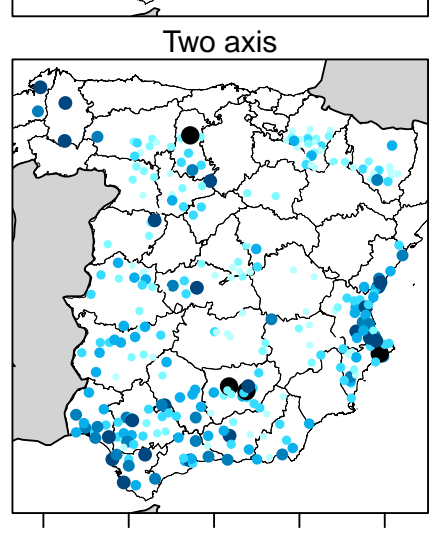

$[0.06,0.095)$

[0.06, $0.095,0.15)$

$0.15,0.27)$

$[0.15,0.27)$

(b) Map

Figure A.6: Relative differences of the yearly values of horizontal (equation (1)) and effective irradiation (equation (2)) between CM SAF and SIAR for the whole set of SIAR stations. 


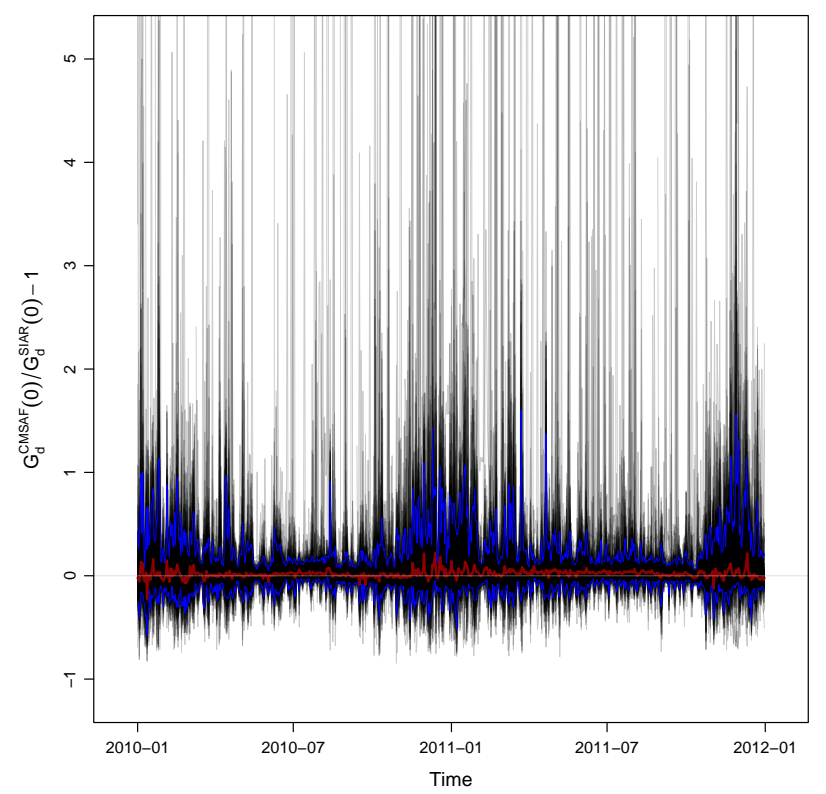

Figure A.7: Time evolution of the relative differences between the daily global irradiation on the horizontal plane from SIAR and CM SAF. The red line represents the median and the blue lines represent the $5 \%$ and $95 \%$ quantiles. 


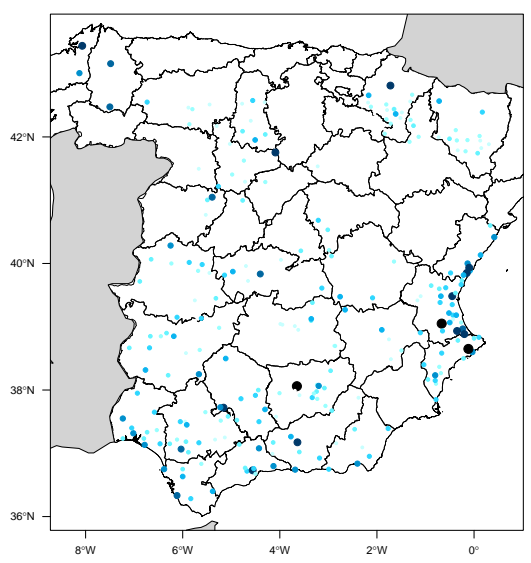

(a) Absolute value of the MBD

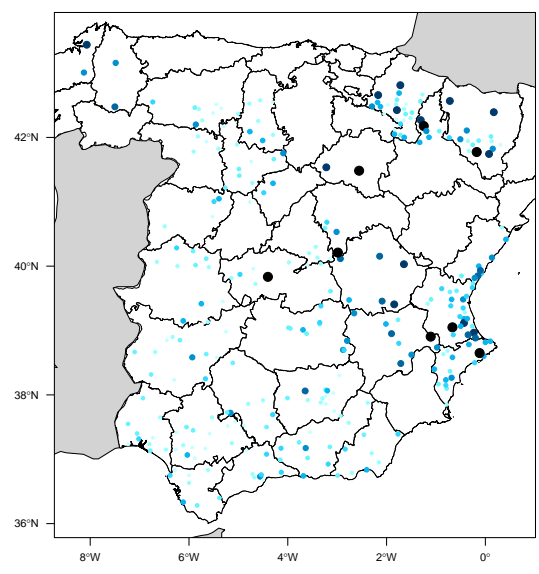

(c) RMSD

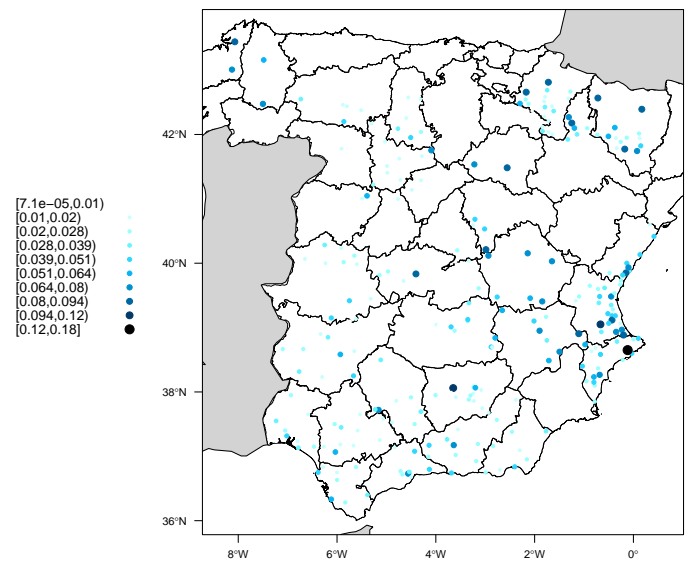

(b) MAD
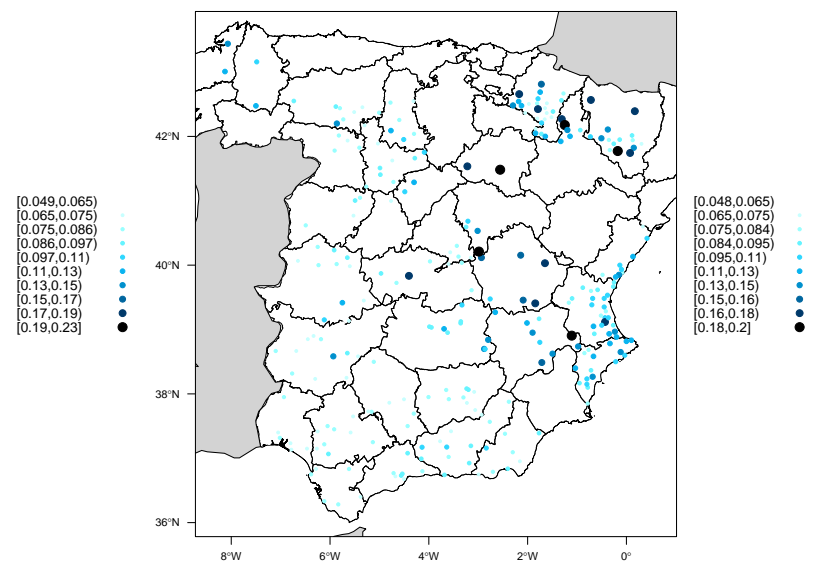

(d) RMSDc

Figure A.8: Statistics of the daily global irradiation on the horizontal plane from SIAR and CM SAF. 


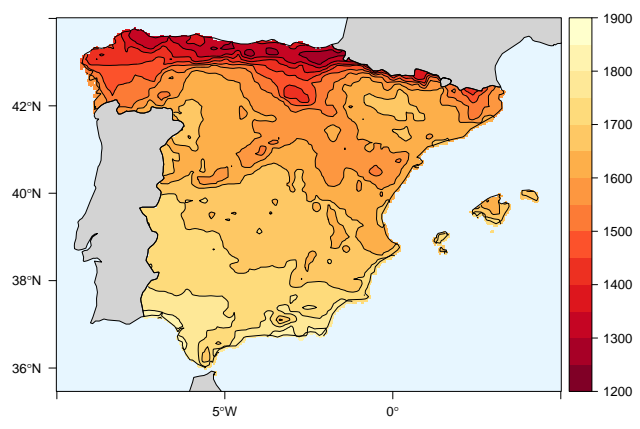

(a) G0

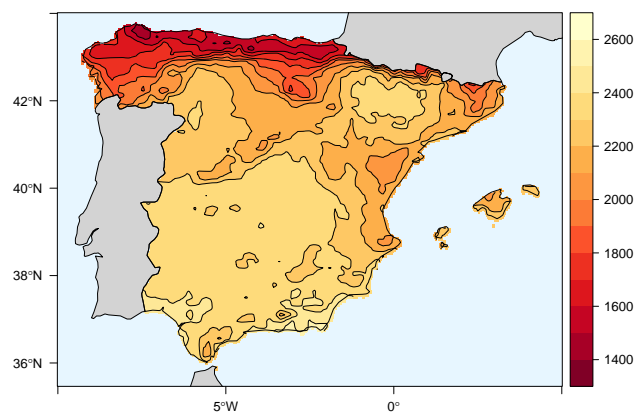

(c) NS Horiz

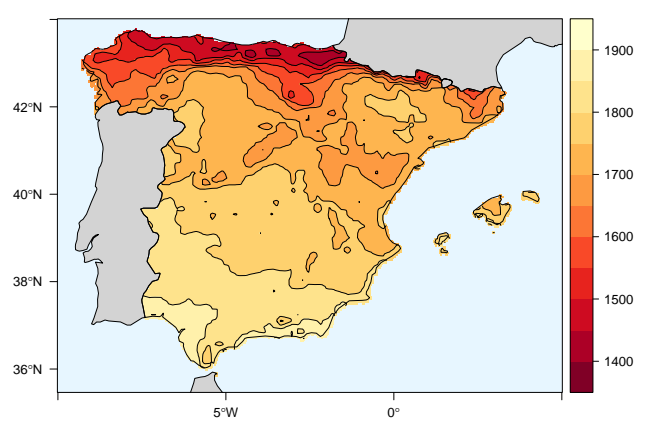

(b) Fixed

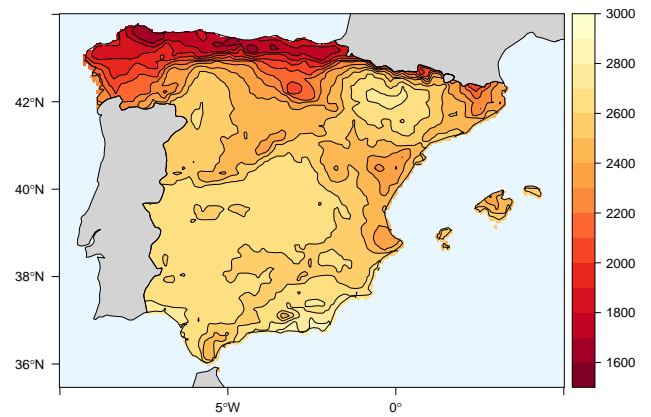

(d) Two

Figure A.9: Global solar irradiation estimated with KED using CM SAF as external drift.

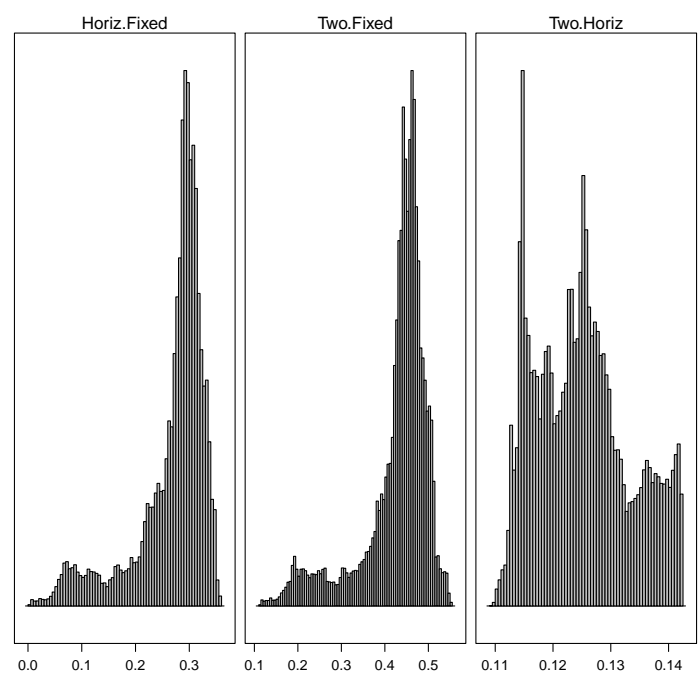

Figure A.10: Histograms of the normalized differences between the effective irradiation incident on a fixed plane, a North-South horizontal axis tracker, and a two-axis tracker. 


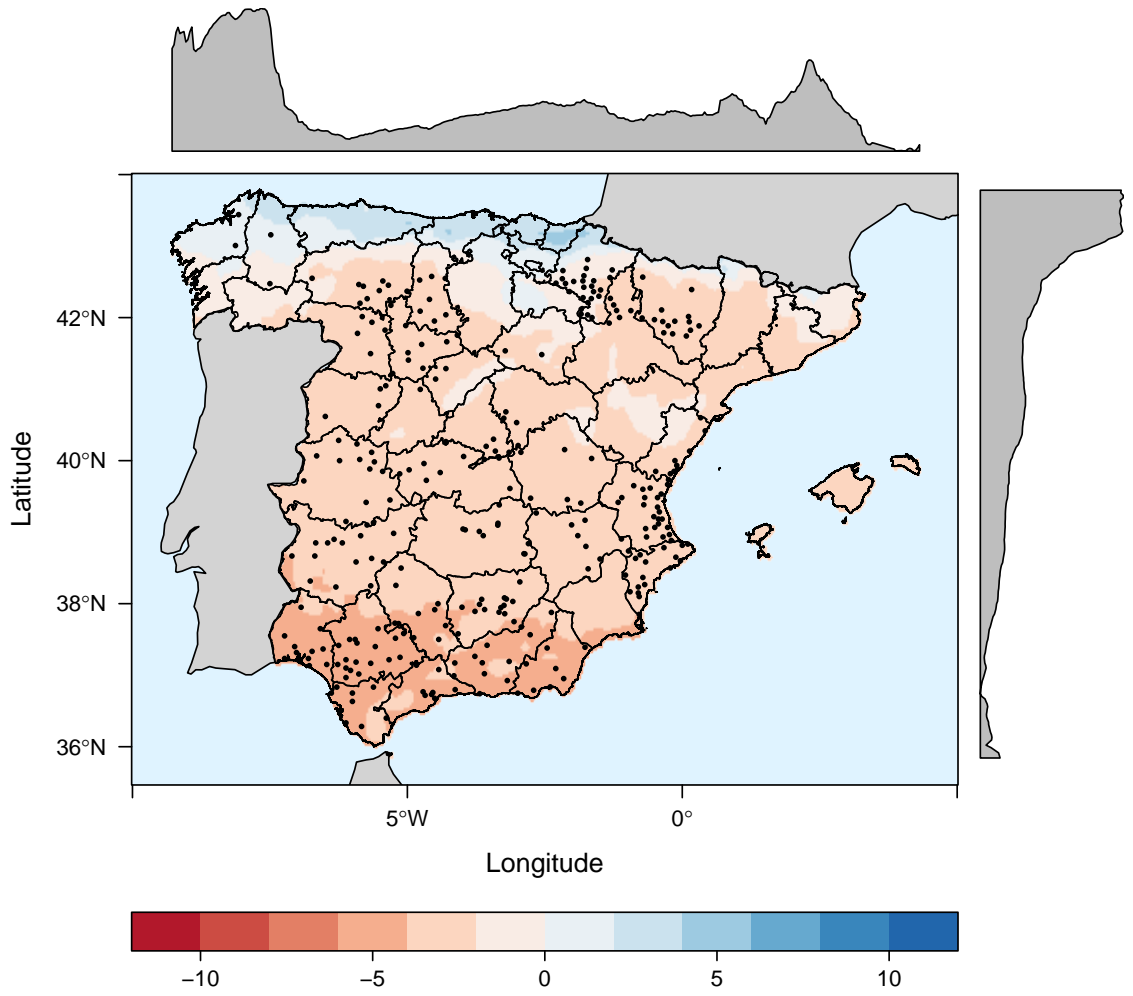

Figure A.11: Relative differences (\%) between the horizontal irradiation estimated with kriging of the values at the SIAR stations using the $G_{y}(0)$ from CM SAF as external drift, and the horizontal irradiation estimated from CM SAF. Positive values mean that the estimation with kriging is higher than with CM SAF. 


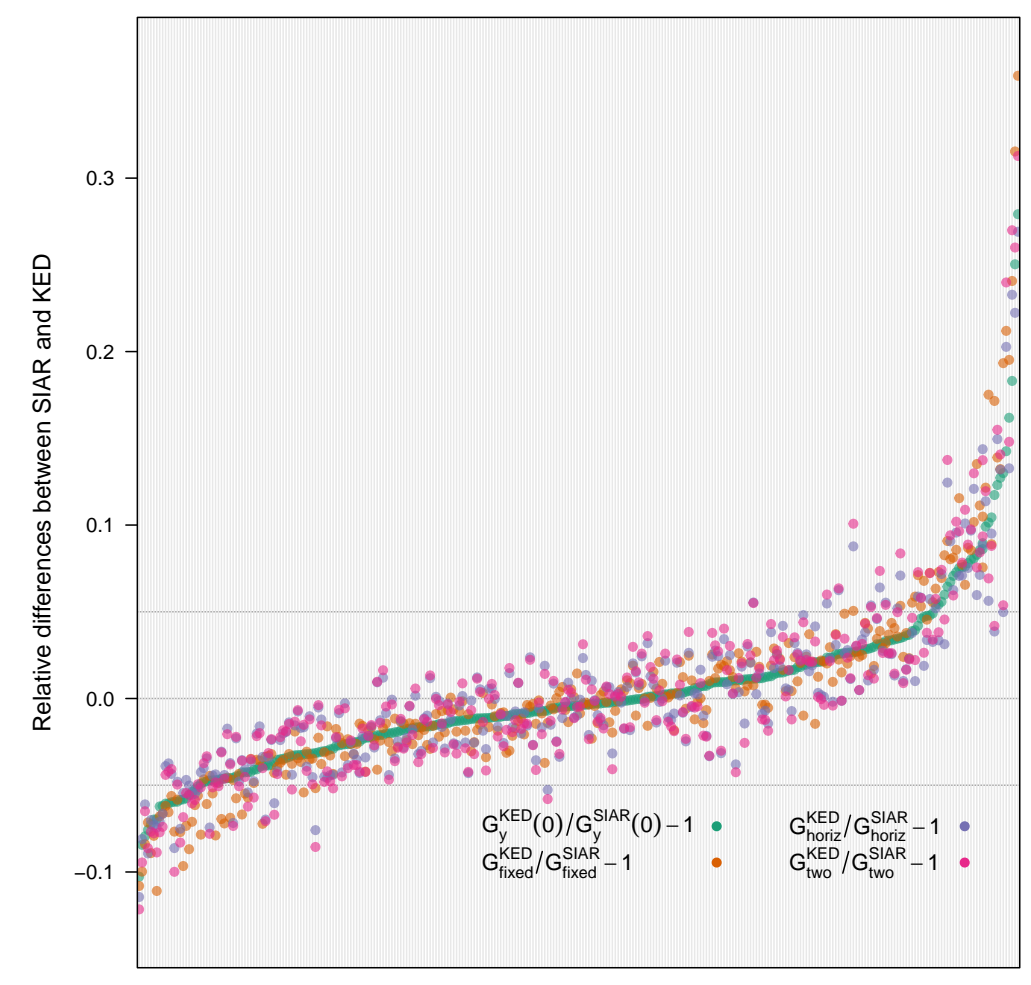

(a) Dotplot
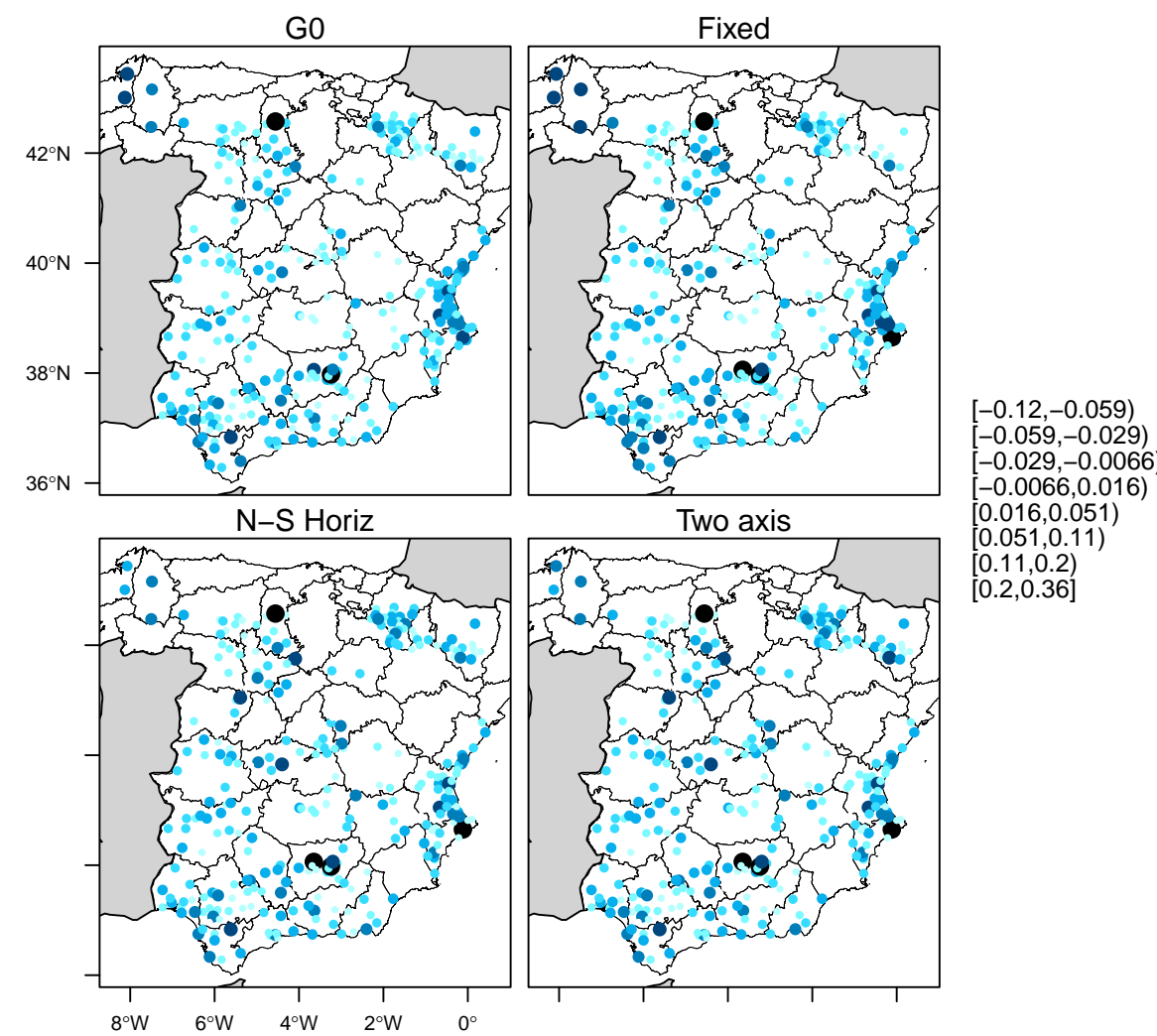

$-0.029,-0.0066)$ 0.016,0.051) $0.051,0.11)$

$0.11,0.2)$

$[0.2,0.36]$

(b) Map

Figure A.12: Relative differences of the yearly values of horizontal (equation (3)) and effective irradiation (equation (4)) between KED and SIAR for the whole set of SIAR stations. 


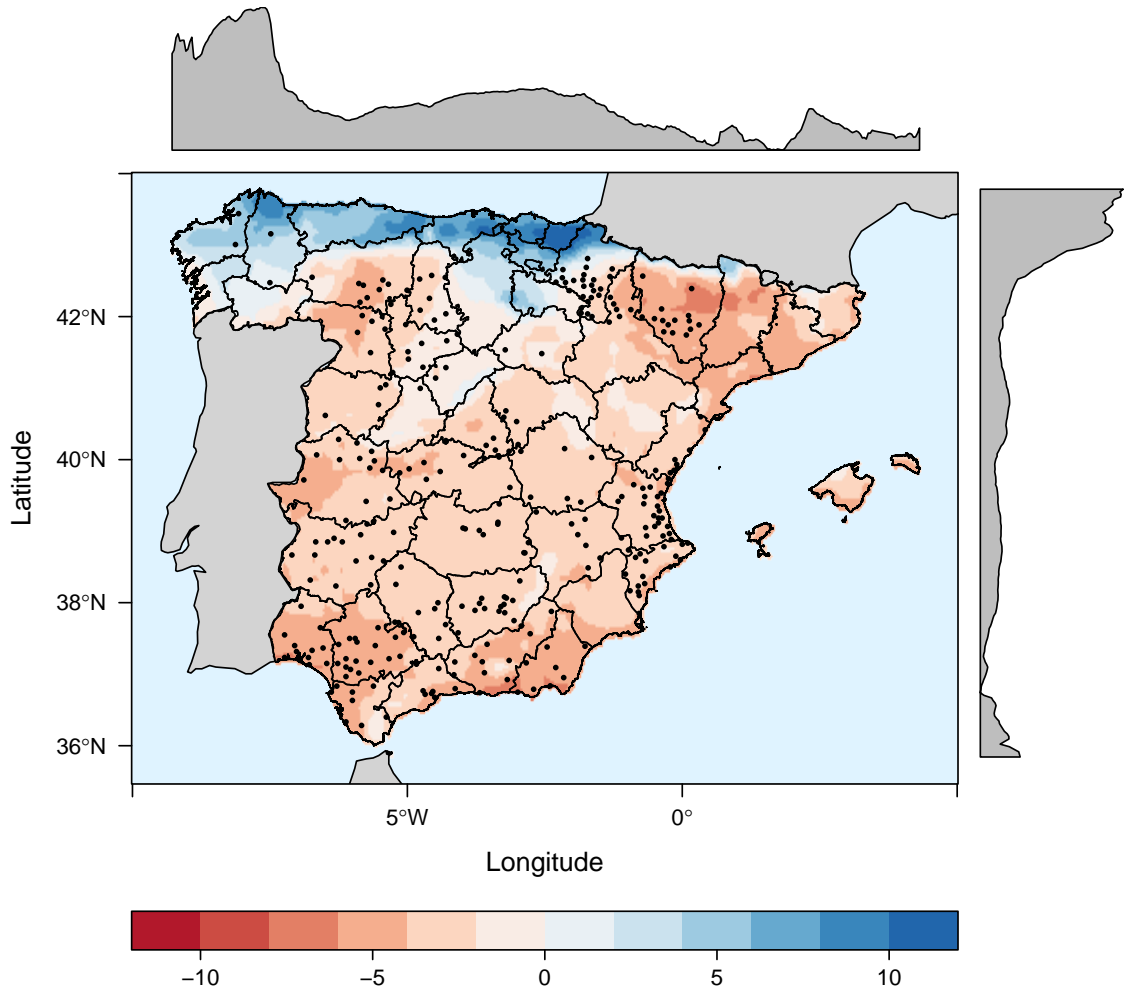

Figure A.13: Relative differences (\%) between the effective irradiation incident on a fixed plane estimated with kriging of the values at the SIAR stations using the $G_{y}(0)$ from CM SAF as external drift, and the effective irradiation estimated with the CM SAF raster. Positive values mean that the estimation with kriging is higher than with CM SAF. 


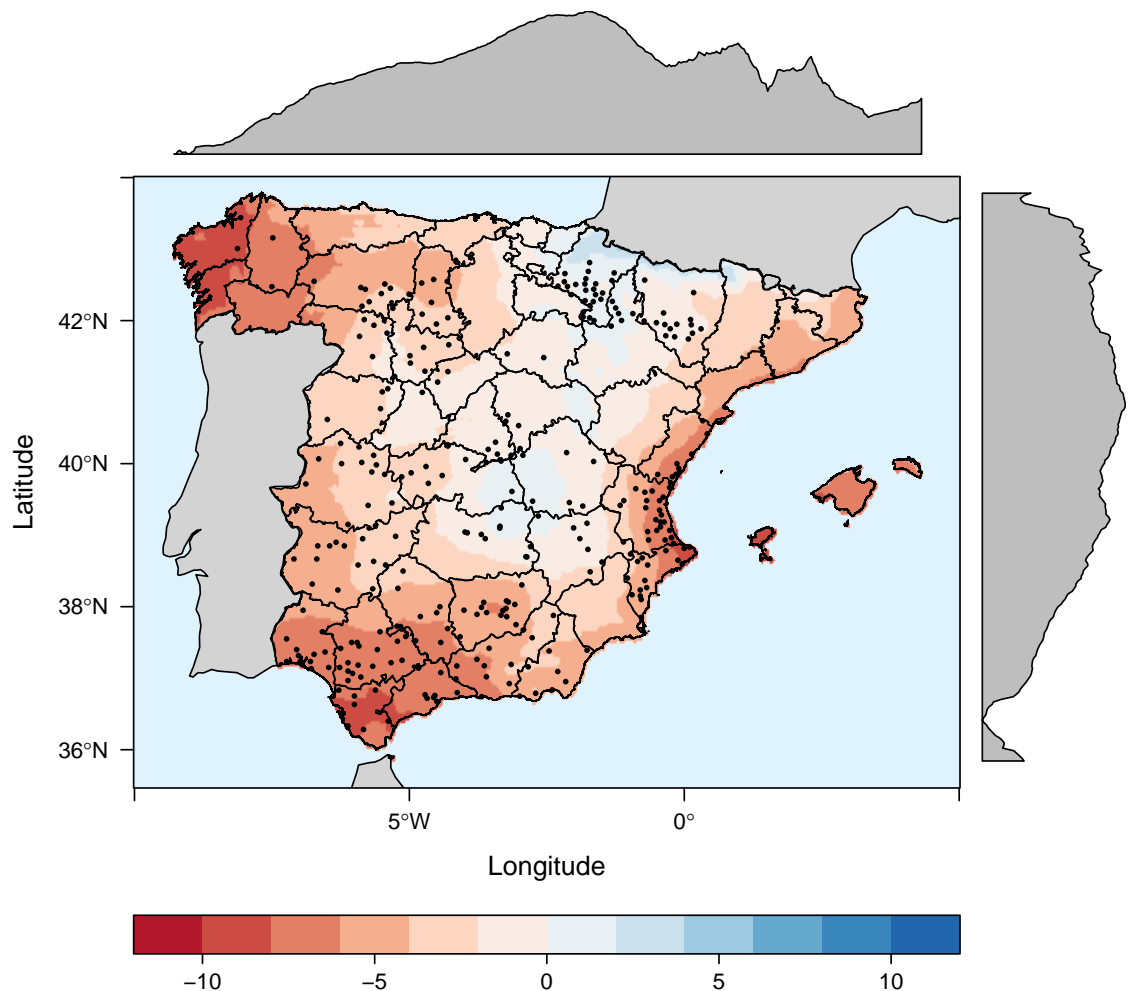

Figure A.14: Relative differences (\%) between the effective irradiation incident on a North-South horizontal axis tracker estimated with kriging of the values at the SIAR stations using the $G_{y}(0)$ from CM SAF as external drift, and the effective irradiation estimated with the CM SAF raster. Positive values mean that the estimation with kriging is higher than with CM SAF. 


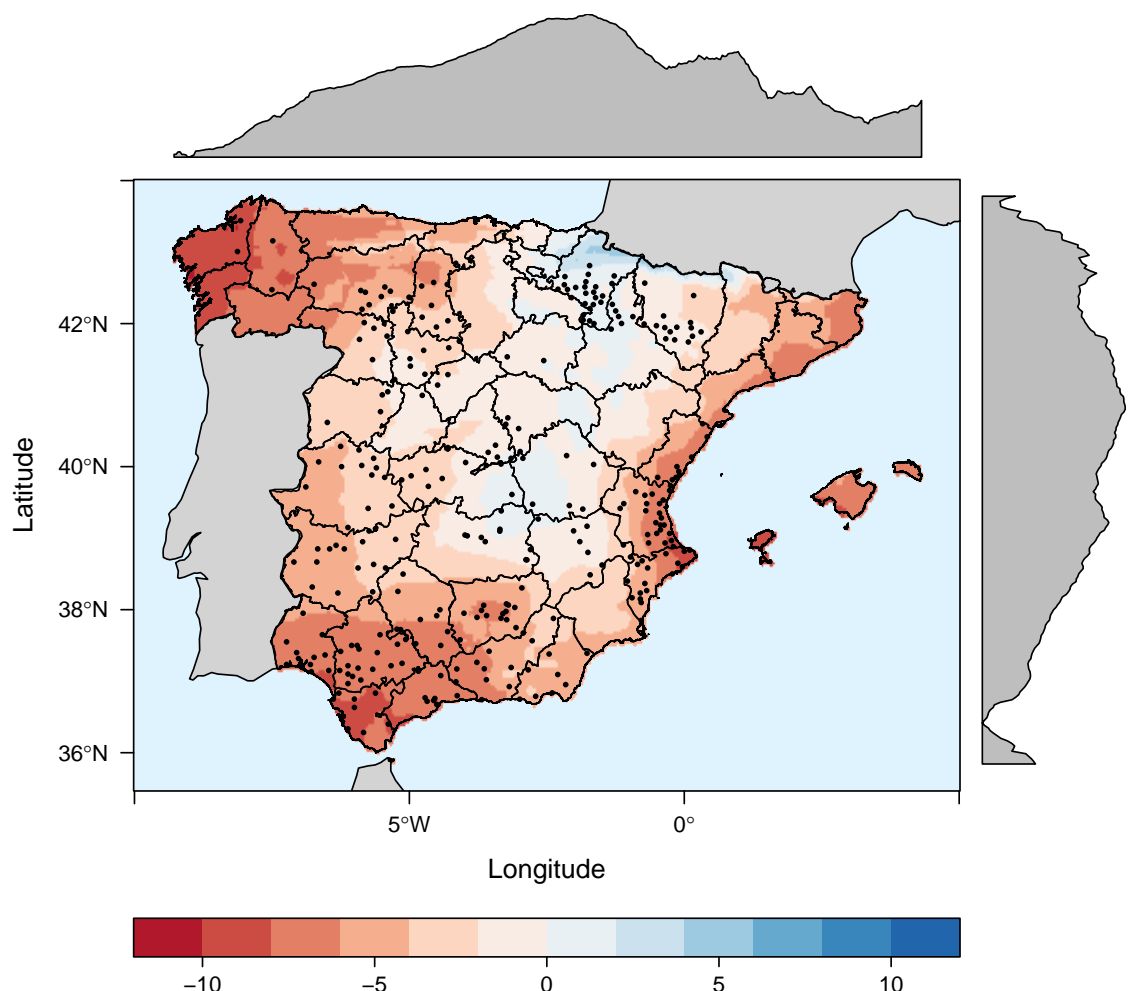

Figure A.15: Relative differences (\%) between the effective irradiation incident on a two-axis tracker estimated with kriging of the values at the SIAR stations using the $G_{y}(0)$ from CM SAF as external drift, and the effective irradiation estimated with the CM SAF raster. Positive values mean that the estimation with kriging is higher than with CM SAF. 


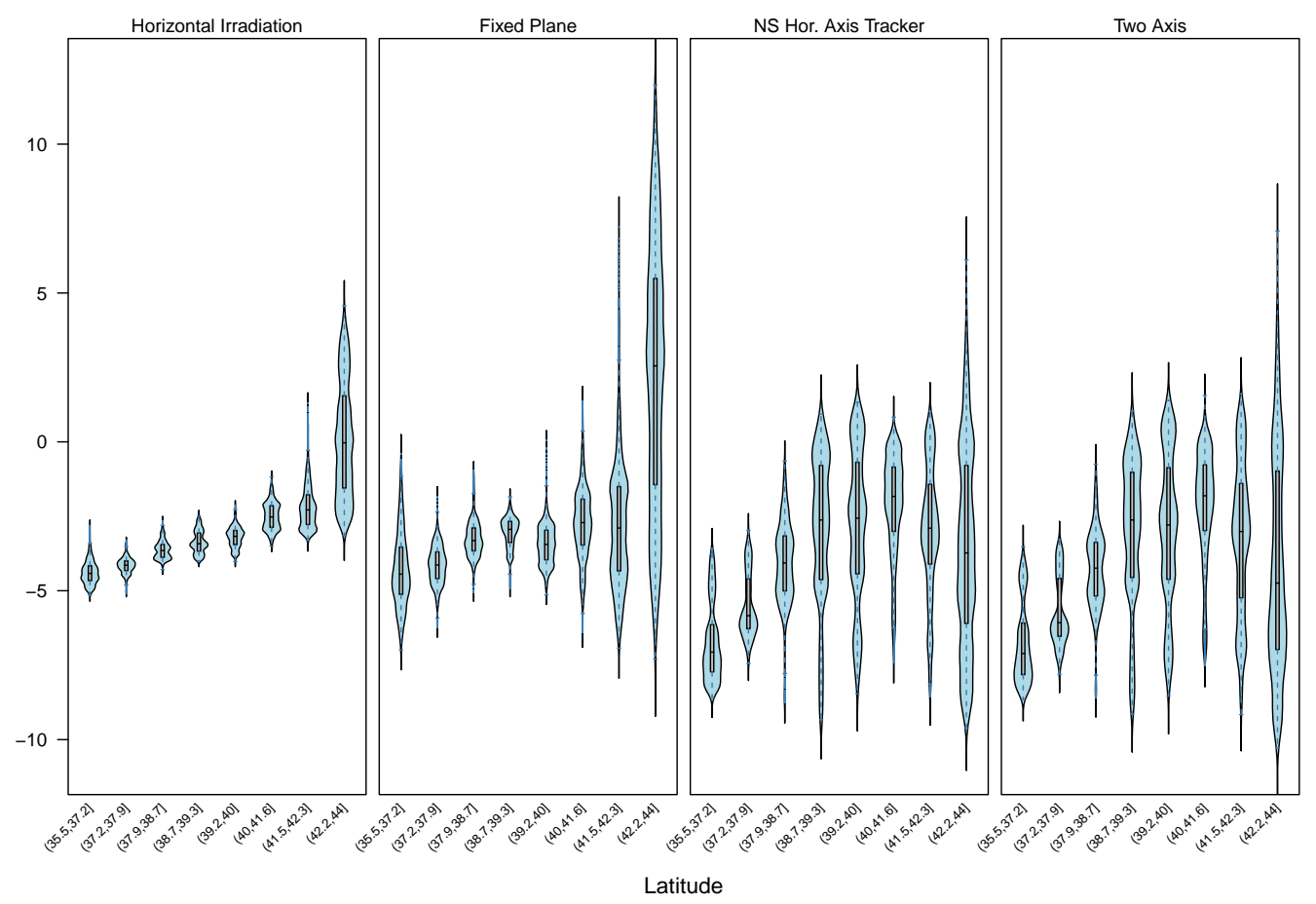

Figure A.16: Violin plot of the relative differences (\%) between irradation estimated with kriging of the values at the SIAR stations using CM SAF as external drift, and the irradiation estimated with the CM SAF raster. Positive values mean that the estimation with kriging is higher than with CM SAF. Each latitude interval include between 41 and 43 stations with an overlap of $10 \%$. 